


\title{
DYNAMIC STIFFNESS OF A GRAVITY BASED FOUNDATION IN OFFSHORE STRUCTURE: DEPENDENCE OF SOIL PROPERTIES IN GLOBAL DAMPING
}

\author{
Master Thesis
}

\author{
By
}

Altantsetseg Perridon

Building Engineer

\begin{abstract}
Advisor
Alejandro E. Martínez Castro

Department of Structural Mechanics and Hydraulic Engineering, University of Granada

Edificio Politécnico Fuentenueva, C/ Severo Ochoa s/n, CP 18002

Granada, Spain
\end{abstract}

September 2016 

(c) Copyright 2016

by

Altantsetseg Perridon 



\section{Summary}

Designing foundations for offshore wind turbines (OWT's) are challenging, in order to ensure reliable and cost-effective designs, the effects of the support structure and the subsoil on the natural vibration characteristics have to be taken into account during the dynamic simulation of the structural response.

The focus of this work is to evaluate the influence of the multi-layered strata on the magnitude of the soil-structure interaction (SSI) of gravity-based structure (GBS) foundations. To do so, a simplified model is proposed for the computation of impedance functions including the SSI effects. The result will be obtained using 3D boundary element program "BEASSI" and "SAP2000". 



\section{Acknowledgements}

First and foremost, I would like to express my deepest gratitude to Prof. Alejandro E. Martínez Castro, for his invaluable guidance, cooperation and constant encouragement during the course of the project.

Thank you for being patient and helping me improve. Without his support, I could not have done what I was able to do.

And also I would especially like to thank to my family and all my friends for their support and constant encouragement I have gotten over the years, without them I would not find the courage to finish this thesis.

I want to dedicate this thesis to my grandparents, who are still waiting for my return to my homeland. 



\section{Contents}

Summary $\quad$ iii

Acknowledgements $\quad$ v

Chapter 1 Introduction, objectives and methodology 1

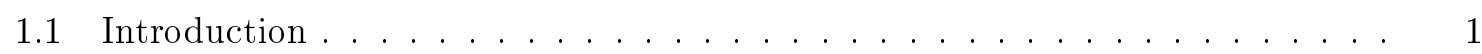

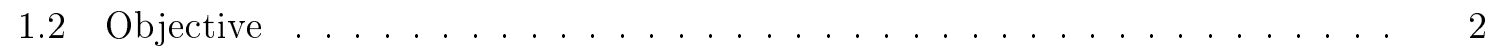

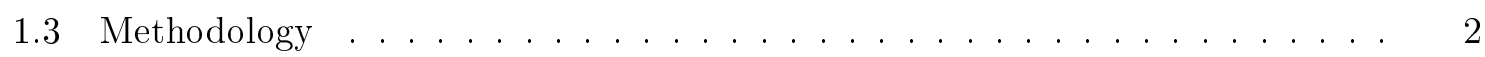

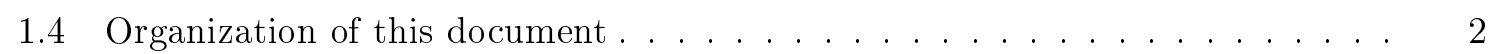

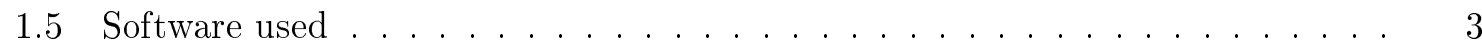

Chapter 2 Damping of offshore wind turbines 5

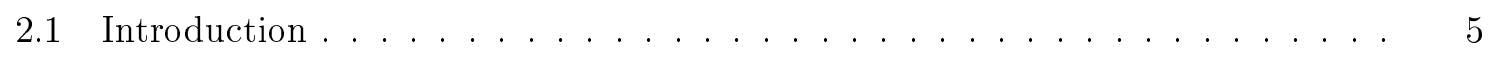

2.2 Dynamic impedance definition . . . . . . . . . . . . . . . 6

Chapter 3 Modelling Considerations 11

3.1 Structural damping . . . . . . . . . . . . . . . . . . . . . . . 11

3.2 Element size . . . . . . . . . . . . . . . . . . . 12

3.3 Analytical validation . . . . . . . . . . . . . . . . . 13

$\begin{array}{lll}\text { Chapter } 4 & \text { Problem statement } & 15\end{array}$

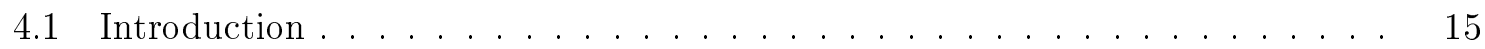

4.2 Dynamic stiffness using 3D boundary element program BEASSI . . . . . . . . . . 17

4.2 .1 Variation of Young's modulus $10 \% \ldots \ldots \ldots$. . . . . . . 17

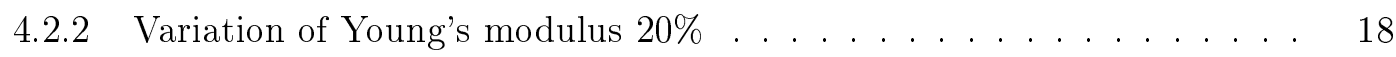

4.2 .3 Variation of Young's modulus $30 \% \ldots \ldots \ldots$

4.3 Coupled model . . . . . . . . . . . . . . . . . . . . . . . . . . 19

$\begin{array}{lll}\text { Chapter } 5 & \text { Conclusions and future works } & 31\end{array}$

5.1 Concluding remarks . . . . . . . . . . . . . . . . 31

$\begin{array}{ll}\text { References } & 32\end{array}$ 



\section{List of Tables}

3.1 Comparison between simple formulation provided by DNV from figure 2.3 and "BEASSI" . . . . . . . . . . . . . . . . . . . . . 14

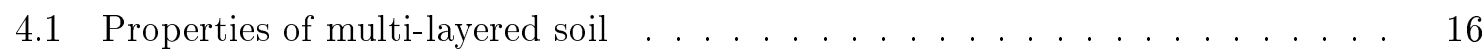

4.2 Dynamic stiffness on five layered strata(reference strata) . . . . . . . . . . 17

4.3 Dynamic stiffness after increasing Young's modulus of each layer $10 \%$. . . . 18

4.4 Dynamic stiffness after increasing Young's modulus of each layer 20\% . . . . 18

4.5 Dynamic stiffness after increasing Young's modulus of each layer $30 \%$. . . . 18

4.6 Mass parameters for SSI . . . . . . . . . . . . . . . . . . . . 21 



\section{List of Figures}

2.1 Degrees of freedom for rigid surface foundation resting on a layered half-space 6

2.2 Downwards and upwards wave propagation for surface disk in layered halfspace, according to $\operatorname{Ref}[1] \ldots \ldots \ldots \ldots$. . . . . . . . . 8

2.3 Stiffness and damping for circular foundations . . . . . . . . . . . . 9

3.1 Damping ratio average in terms of the $\%$ load level. . . . . . . . . . . . . 12

3.2 Mesh dependency . . . . . . . . . . . . . . . . . . . . . . 13

4.1 A gravity based foundation on a multi-layered soil . . . . . . . . . . . . 16

4.2 Schematic model of an offshore wind turbine for SAP2000 . . . . . . . . . . 19

4.3 Coupled model SAP2000 . . . . . . . . . . . . . . . . . . . . 20

4.4 Reference Displacement . . . . . . . . . . . . . . . . . . . . 21

4.5 Reference Acceleration . . . . . . . . . . . . . . . . . . . . 21

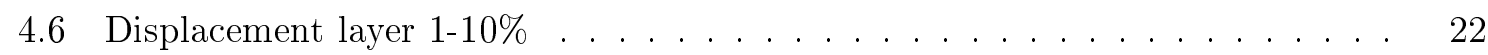

4.7 Acceleration Layer $1-10 \% \ldots \ldots \ldots \ldots \ldots$

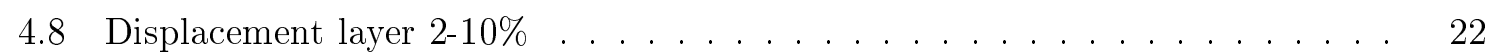

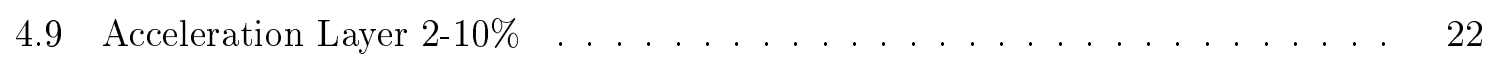

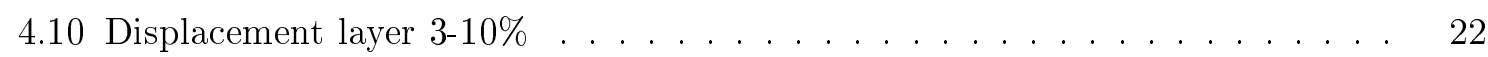

4.11 Acceleration Layer $3-10 \% \ldots \ldots \ldots \ldots . \ldots \ldots . \ldots \ldots$

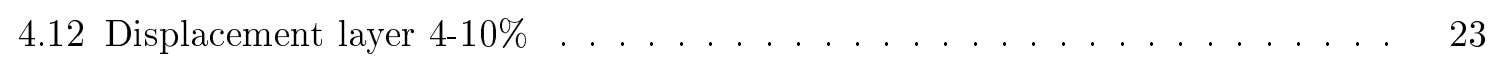

4.13 Acceleration Layer $4-10 \% \ldots \ldots \ldots . \ldots \ldots$

4.14 Displacement layer $5-10 \% \ldots \ldots \ldots \ldots \ldots \ldots$

4.15 Acceleration Layer $5-10 \% \ldots \ldots \ldots \ldots \ldots$

4.16 Displacement layer $1-20 \%$. . . . . . . . . . . . . . . . . . 23

4.17 Acceleration Layer $1-20 \% \ldots \ldots \ldots \ldots . \ldots \ldots . \ldots \ldots$

4.18 Displacement layer $2-20 \%$. . . . . . . . . . . . . . . . . . 24

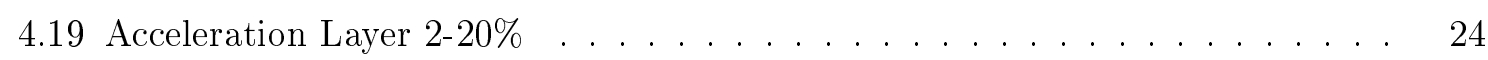

4.20 Displacement layer $3-20 \%$. . . . . . . . . . . . . . . . . . . 24

4.21 Acceleration Layer $3-20 \% \ldots \ldots \ldots$

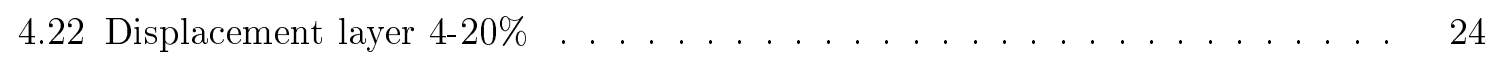

4.23 Acceleration Layer $4-20 \% \ldots \ldots \ldots$. . . . . . . . . . . . 24

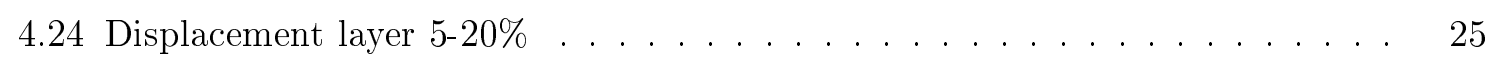

4.25 Acceleration Layer $5-20 \% \ldots \ldots \ldots \ldots \ldots \ldots$

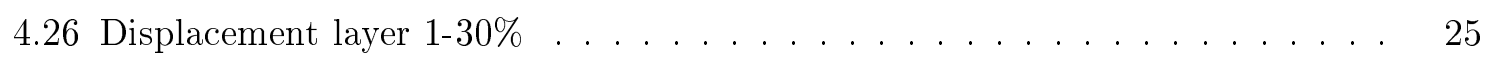

4.27 Acceleration Layer $1-30 \% \ldots \ldots \ldots \ldots \ldots$ 


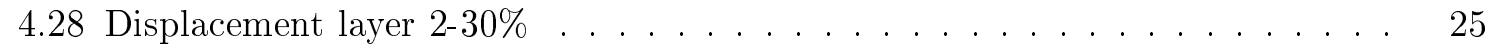

4.29 Acceleration Layer $2-30 \% \ldots \ldots \ldots \ldots \ldots \ldots$

4.30 Displacement layer $3-30 \% \ldots \ldots \ldots \ldots \ldots \ldots$

4.31 Acceleration Layer $3-30 \% \ldots \ldots \ldots \ldots \ldots$

4.32 Displacement layer $4-30 \% \ldots \ldots \ldots \ldots \ldots$

4.33 Acceleration Layer $4-30 \% \ldots \ldots \ldots \ldots \ldots$

4.34 Displacement layer $5-30 \% \ldots \ldots \ldots \ldots \ldots \ldots$

4.35 Acceleration Layer $5-30 \% \ldots \ldots \ldots \ldots \ldots$

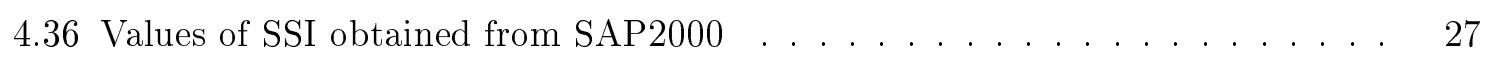

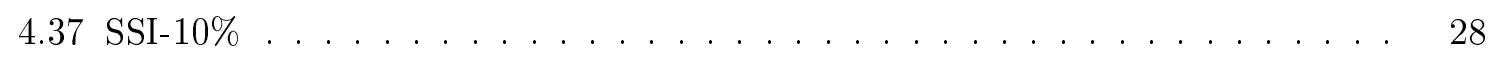

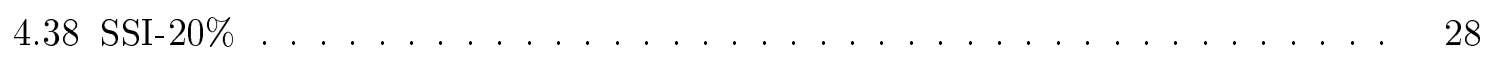

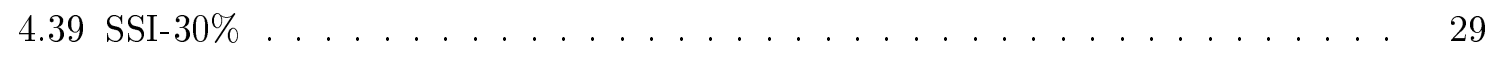

4.40 Comparison between variations of Young's modulus . . . . . . . . . . . 29 


\section{CHAPter 1}

\section{Introduction, objectives and methodology}

\subsection{Introduction}

Modern wind turbines are constantly increasing in size with larger rotors and more powerful generators. The costs are kept as low as possible by reducing the overall weight, which leads to slender and flexible structures sensitive to the dynamic amplification of the response from wave- and wind-induced loads. This in turn necessitates a reliable estimate of the basic dynamic properties of the entire wind turbine structure in order to decrease the fatigue damage accumulation. In this regard, the wave propagation in the subsoil emitted from the vibrations on the soil-foundation interface is crucial to consider. To deal with this soil-structure interaction problem, sub-structuring technique is normally employed. In the application of sub-structuring technique, the surrounding soil of structural foundation is represented by an impedance matrix, which can then be combined into total stiffness matrix of finite element model of structure for soil-structure interaction analysis. Therefore, to effectively and efficiently generate impedance matrix is an important step for the soil-structure interaction analysis.

For evaluating the impedance of OWT foundations exist several methods, among these the finite-element method with radiating and transmitting boundary conditions suggested by Higdon [2,3] and Krenk [4], the boundary-element method, the domain-transformation method, analytical and semi analytical approaches. Based on transfer matrices for a layered half-space, originally proposed by Haskell [5] and Thomson [6], Andersen and Clausen [7], Andersen [8] and Damgaard et al. [9] used the domain-transformation method [10] for a rigid surface foundation on a horizontal viscoelastic stratum and proved that the impedance in terms of its magnitude and phase angle followed a second order polynomial without any resonance peaks. However, the presence of stratified soil showed a drastic change in the frequency response with local tips and dips.

Similar conclusions were drawn by Emperador and Domínguez [11], Liingaard et al. [12], Andersen and Liingaard [13] and Andersen et al. [14], who used boundary element and coupled boundary-element/finite-element models to investigate the frequency dependent stiffness of axisymmetric embedded foundations. In addition, Krenk [15] analysed the vertical impedance of a flexible circular foundation on a homogeneous ground, whereas Yong et al. [16] studied a layered soil. Luco and Westmann [17] applied prescribed conditions under a rigid massless surface foundation and zero traction at the remaining free surface of a homogeneous elastic 
half-space in order to solve the system as a mixed boundary-value problem for studying the torsional vibrations. For the same degree of freedom, Veletsos and Damodaran Nair [18] investigated the influence of material damping, while closed-form solutions of the impedance were reported by Novak and Sachs [19] and Avilés and Pérez-Rocha [20].

Furthermore, Wong and Luco [21] evaluated the impedance functions for a rigid square foundation on a viscoelastic half-space by solving an integral equation involving the Green's function. For a similar foundation type, Mita and Luco [22] evaluated the impedance functions by means of a hybrid approach. Finally, the coupled horizontal and rocking vibrations of surface foundations were reported by Veletsos and Wei [23] and Ahmad and Rupani [24] as well as Bu and Lin [25].

For laterally and vertically loaded monopiles and jackets, the soil structure interaction is traditionally analysed by means of a nonlinear Winkler foundation approach, in which the pile is continuously supported by nonlinear uncoupled springs and dashpots to represent the horizontal and vertical soil resistance and damping characteristic. Following this approach, El Naggar and Novak [26-29], El Naggar and Bentley [30], Kong et al. [31], Allotey and El Naggar [32], Memarpour et al. [33], Andersen et al. [34] and Damgaard et al. [35] investigated the vibration response and dynamic properties of monopile structures. However, using this approach for fast time domain analysis in aeroelastic codes does not seems obvious, since only the soil-foundation interface is important with regard to the dynamic structural behaviour of the wind turbine.

\subsection{Objective}

The objective of this work is to evaluate the influence of the multi-layered strata on the magnitude of the soil-structure interaction (SSI) of gravity-based foundations. To reach the proposed objective, a rigid square foundation is attached to a multi-layered soil and subjected to torsional, vertical, rocking and horizontal excitations to study the impedance matrices for different combinations of soil properties in order to show the effect of the multi-layered strata on SSI.

\subsection{Methodology}

To reach the previous objective, the following methodology is applied.

- To develop dynamic matrix, a general overview of dynamic impedance is carried out.

- Several modelling considerations are taken account, such as structural damping, element size and analytical validation.

- The problem statement and solutions are exposed.

\subsection{Organization of this document}

This project is organized by chapters, which are dependent between each of them. This way each chapter is connected to the next one. The first chapter will introduce earlier works of different authors on this subject and their conclusions and general overview of dynamic impedance to give basic information. 
In the second chapter explains the modelling considerations which will be taken account to provide the required information to proceed with the calculation of foundation impedances using 3D boundary element program "BEASSI" and "SAP2000".

The last chapter introduces the problem statement and the result drawn from "BEASSI" and "SAP2000".

\subsection{Software used}

The following computer programs were used in this thesis:

- BEASSI, Boundary Element Analysis of Soil Structure Interaction

- SAP2000, Integrated Software for Structural Analysis and Design

- EXCEL, spreadsheet program, Microsoft Inc. 



\section{Chapter 2}

\section{Damping of offshore wind turbines}

\subsection{Introduction}

The development of offshore wind turbines (OWT's) faces new challenges for the support structure, a greater random environmental load demand. These increased offshore wind speeds result in a much greater demand on monopile support structures, as resonance generated by stochastic wind, wave and mechanical loading causes them to fall subject to accelerated cyclic fatigue.

When a structural element is in contact with the ground, the structural displacements and the ground displacements are not independent of each other. The process by which the response of the structure affects the response of the underlying soil and by which the response of the soil affects the response of the structure is known as soil-structure interaction (SSI).

It is well known that the dynamic response of a structure on a flexible soil may be different from the response of a similarly excited structure supported on firm soil. Veletsos and Verbic [36] showed that the presence of flexible soil underneath the foundation of a structure increases the damping capacity of the foundation and reduces the structure's natural frequency. Luco [37], in a study on seismic response of tall chimneys, showed that soil-structure-interaction (SSI) had an effect only for softer soils and could lead to reductions or increases in response, depending on the characteristics of the chimney and the seismic excitation. Luco's work was verified by Moghaddasi et al. [38] who carried out a Monte Carlo simulation for a range of single degree of freedom (SDOF) structures and soil conditions excited by a series of seismic excitations. Novak and Hifnawy $[39,40]$ showed that the response of a structure when subject to dynamic wind loading can be affected by SSI. A full review of the development of SSI can be found in Kausel [41].

Zaaijer [42] modelled the dynamic behaviour of foundations of offshore wind turbines. The author investigated the sensitivity of the support structure's natural frequency to variation in foundation types. This work was extended by Camp et al. [43]. Particular attention was paid to the uncertainty of several key geotechnical design parameters. The report found that the sensitivity of gravity base foundations to soil parameters is higher than for piled foundations, lending to the presumption that gravity base foundations cannot be uniform within a wind farm, but rather designed for local soil conditions at the location of the foundations. 
During the operation of an offshore wind turbine the displacement of the subsoil structure causes a cyclic motion of the surrounding soil, leading to a combination of radiation damping and material damping. [44]

- Radiation damping: This damping is also referenced as geometrical damping and is due to the radiation boundary condition at large distances from the foundation. This damping source can be determined by computations in the frequency domain. In linear theory, it only depends on the foundation size, and the soil elastic parameters (elastic or poroelastic behaviour). DNV [45] suggest its evaluation when SSI is relevant for the design. For GBS the main damping contribution comes from this term.

- Material damping: Damping caused by viscoelastic behaviour of the material. This damping is considered in frequency-domain by complex-valued damping rates.

\subsection{Dynamic impedance definition}

The response of a rigid foundation to static or dynamic load solely from the deformation of the supporting soil. The static soil stiffness $(K=F / U)$ is used to model the soilstructure(foundation) response to static load. In an analogous manner, the dynamic soil impedance/stiffness $(K=F(t) / U(t))$ is used to model the soil-structure(foundation) response to dynamic loads. In particular, six dynamic impedances are required, three translational and three rotational, to formulate the dynamic equilibrium equation of a rigid foundation, as shown in Figure 2.1.

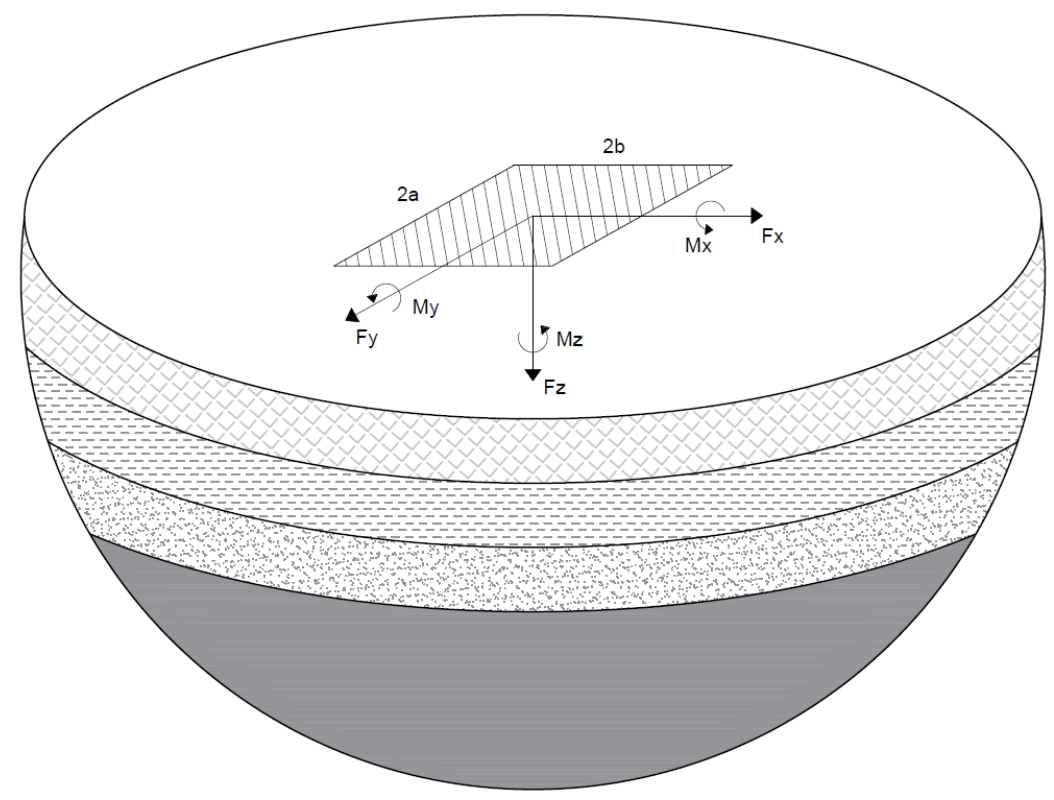

Figure 2.1: Degrees of freedom for rigid surface foundation resting on a layered half-space

The dynamic equilibrium equation that determines the foundation behaviour under dynamic loads has the following expression: 


$$
M \ddot{u}(t)+C \dot{u}(t)+K u(t)=F(t)
$$

where $M, C$ and $K$ are the mass, damping and stiffness matrices respectively, $u(t)$ the vector of nodal displacements and $F(t)$ the vector of external nodal loads.

Using new dynamic variables for natural frequency, $\omega_{n}$, and damping ratio, $\xi$, the equation of motion can re-write. Note that

$$
\begin{gathered}
\frac{C}{M}=2 \xi \omega_{n} \\
\ddot{u}(t)+\left(\frac{C}{M}\right) \dot{u}(t)+\left(\frac{K}{M}\right) u(t)=\frac{F(t)}{M} \\
\ddot{u}(t)+2 \xi \omega_{n} \dot{u}(t)+\omega_{n}^{2} u(t)=\frac{F(t)}{M}
\end{gathered}
$$

From Eq. 2.3 and 2.4, the damping ratio $\xi$ can be obtained

$$
\xi=\frac{C}{2 M \omega_{n}}
$$

Considering harmonic loads $\left(u(t)=U e^{i \omega t}\right.$ and $\left.F(t)=F e^{i \omega t}\right)$. Substituting these statements into the dynamic equilibrium equation given by Eq. 2.1, the following frequency domain equation can be obtained.

$$
\left[K-\omega^{2} M+i \omega C\right] U e^{i \omega t}=F e^{i \omega t}
$$

The normalized impedance functions are complex functions of the dimensionless frequency

$$
\bar{\omega}=\frac{\omega a}{C_{s}}
$$

The procedure used to calculate the dynamic impedances of a rigid surface foundation can be summarized in the following steps:

1. The foundation is modelled as massless and rigid; therefore, only the geometry of the area in contact with the soil is required (e.g., $2 \mathrm{a}$ and $2 \mathrm{~b}$ shown in Figure 2.1). The use of a massless foundation is important since it avoids the need for recalculating the dynamic impedance every time that the foundation mass changes, which often happens during the design process.

2. A harmonic force or moment of frequency $\omega$ and of unit magnitude is applied to the rigid foundation (e.g., $F(t)=F e^{i \omega t}$ or $M(t)=M e^{i \omega t}$ ), as shown in Figure 2.2. Such force/moment generates stress waves that propagate into the underlying soil, which is modelled as a viscoelastic material. Therefore, the following properties are required for each soil layer: thickness $(h)$, Young's modulus $(E)$, Poisson's ratio $(\nu)$, density $(\rho)$, and material damping $(\xi)$. 


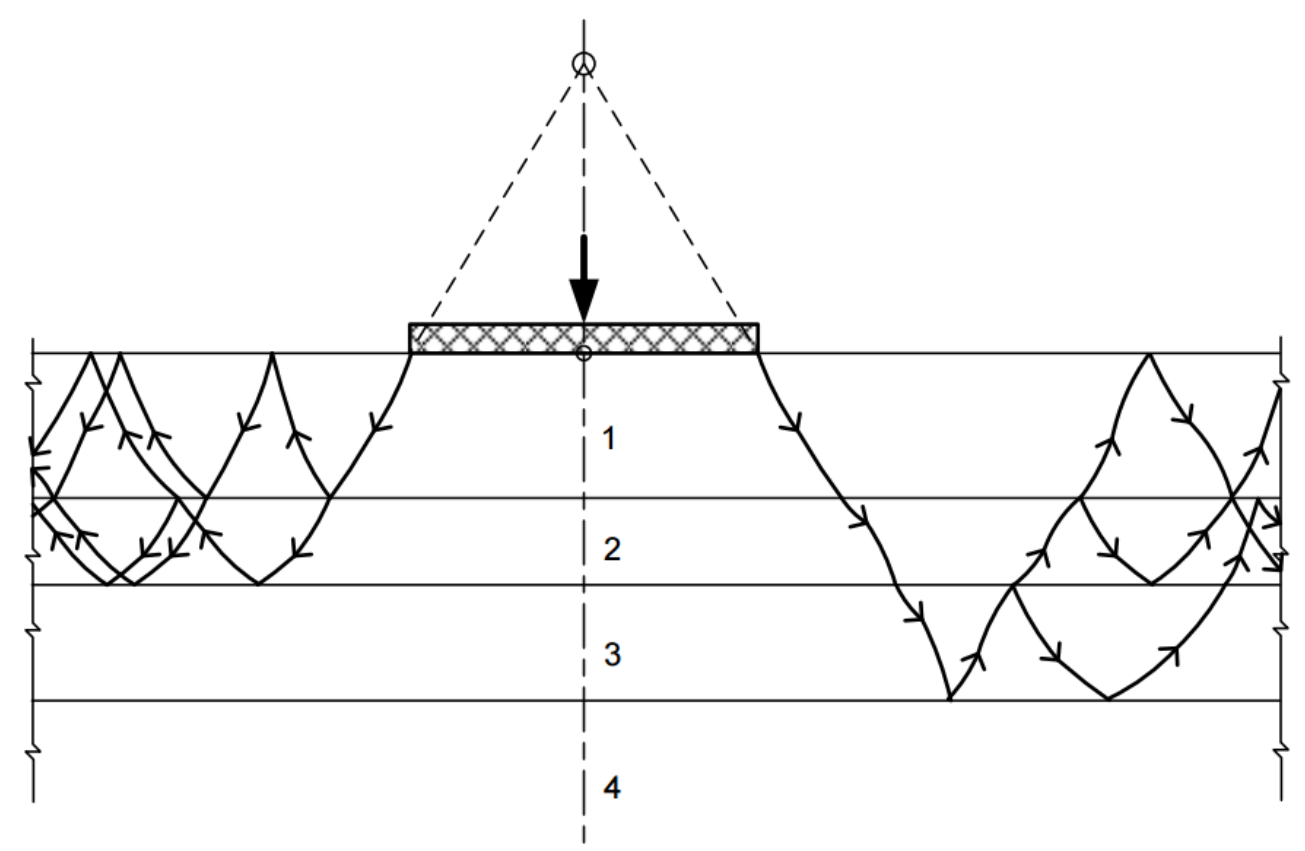

Figure 2.2: Downwards and upwards wave propagation for surface disk in layered half-space, according to Ref [1]

3. The steady state vibration amplitude $\left(U(t)=U e^{i \omega t}\right)$ of the foundation under the harmonic force is obtained by keeping track of the reflections and refractions that take place every time that the stress waves reach a soil layer boundary. This is achieved by finding the different wave paths shown in Figure 2.2.

4. The dynamic impedance $K(\omega)$ is defined as the ratio between the harmonic force acting on the foundation and its vibration amplitude as shown in Eq. 2.8. It must be noted that this is a frequency dependent complex quantity.

$$
K(\omega)=\frac{F(t)}{U(t)}
$$

5. In soil dynamics, it is customary to express the complex dynamic impedance as shown in Eq. 2.9. In addition, the real and imaginary parts of the dynamic impedance are associated, by analogy, with a dynamic (frequency dependent) stiffness and damping as shown in Eq. 2.10.

$$
\begin{gathered}
K(\omega)=\bar{k}+i \omega C \\
\bar{k}(\omega)=\operatorname{Re}(K(\omega)) \\
C(\omega)=\frac{\operatorname{Im}(K(\omega))}{\omega}
\end{gathered}
$$


The real parts of the impedance functions are generally thought of as dynamic stiffness coefficients $\operatorname{Re}(K(\omega))=K-\omega^{2} M$ while the imaginary parts divided by frequency are thought of as damping coefficients $\operatorname{Im}(K(\omega))=i \omega C$.

The DNV document [45] provide simple formulation to evaluate the stiffness and damping coefficient of the main solid-rigid modes of the GBS foundation. Figure 2.3 shows the formulation to estimate the parameters for circular foundation.

\begin{tabular}{|c|c|c|c|}
\hline \multicolumn{4}{|c|}{$\begin{array}{l}\text { Table } 7.1 \text { Spring and damping coefficients, mass and } \\
\text { damping ratios and "effective mass" for a rigid circular } \\
\text { foundation resting on an elastic half space. }\end{array}$} \\
\hline $\begin{array}{l}\text { Mode of } \\
\text { vibration }\end{array}$ & $\begin{array}{l}\text { Spring co- } \\
\text { efficient } k\end{array}$ & $\begin{array}{l}\text { Damping coef- } \\
\text { ficient } c\end{array}$ & $\begin{array}{c}\text { "Effective } \\
\text { mass" }\end{array}$ \\
\hline Vertical (z) & $\frac{4 \mathrm{Gr}_{0}}{1-v}$ & $\frac{3.4 \mathrm{r}_{o}^{2}}{1-v} \sqrt{\rho \mathrm{G}}$ & $\frac{1.08 \rho r_{0}^{3}}{1-v}$ \\
\hline $\begin{array}{l}\text { Horizontal } \\
\text { (x) }\end{array}$ & $\frac{8}{2-v} \mathrm{Gr}_{0}$ & $\frac{4.6}{2-v} \mathrm{r}_{\sigma}^{2} \sqrt{\rho \mathrm{G}}$ & $\frac{0.76 \rho \mathrm{r}_{0}^{3}}{2-v}$ \\
\hline $\begin{array}{l}\text { Rocking } \\
(\psi)\end{array}$ & $\frac{8 \mathrm{Gr}_{\mathrm{o}}^{3}}{3(1-v)}$ & $\frac{0.8 \mathrm{r}_{\circ}^{4} \sqrt{\rho \mathrm{G}}}{(1-v)\left(1+\mathrm{B}_{\psi}\right)}$ & $\frac{0.64 \rho \mathrm{r}_{0}^{5}}{1-v}$ \\
\hline Torsion $(\theta)$ & $\frac{16 \mathrm{Gr}_{0}^{3}}{3}$ & $\frac{4 \mathrm{r}_{0}^{4} \sqrt{\mathrm{B}_{\theta} \rho \mathrm{G}}}{1+2 \mathrm{~B}_{\theta}}$ & $0.24 \rho \mathrm{r}_{0}^{\mathrm{s}}$ \\
\hline$=$ & \multicolumn{3}{|c|}{$\begin{array}{l}=\text { radius of foundation (rectangular foundations } \\
\text { are treated as described in Section G5.2.2.4). } \\
\rho=\text { shear modulus, Poisson's ratio and mass den- } \\
\text { sity of the elastic halfspace. }\end{array}$} \\
\hline
\end{tabular}

Figure 2.3: Stiffness and damping for circular foundations 



\section{CHAPter 3}

\section{Modelling Considerations}

The boundary element method is used to determine the dynamic stiffness of rectangular foundations resting upon within a viscoelastic multi-layered half-space to capture three dimensional effects, the soil layer profile, and the geometry of the foundation. Due to the characteristics of the soil and the excitation periods (from 0.5 to 10 seconds) the saturated half space is modelled with three-dimensional elasticity equations, in which the Poisson's ratio is taken close to 0.5 ( 0.45 in computations) to represent low compressibility conditions and saturated density as the material density at each layer. The purpose of this section is to provide the required information to proceed the calculation of foundation impedances using 3D boundary element program "BEASSI" and "SAP2000".

\subsection{Structural damping}

It is called structural damping when internal friction of a material transforms vibrational energy into heat. The structural damping is considered in modal analysis through the damping rate $\xi$ which relates the damping constant $C$ of the system respect to the critical damping rate.

According to the experimental works (J. Taillon et al. [46]), reveals that for a lattice tower with structural steel, damping rate is non-linear, and it depends on the loads, connections (welded, bolted), etc. Figure 3.1 shows the dependence on the loading level and the damping rate.

The relation between the level of load and damping is also recognized in codes by providing different values, depending on the type of loading. ASCE [47] recommends, in its commentary, to use a value between $0.15 \%$ and $0.5 \%$ for wind effect on steel towers, and $5 \%$ for earthquake. ASCE [48] commentaries recognize that damping can be influenced by the level of structural response. For elastic dynamic analysis, AASHTO [49] recommends a damping ratio of $1 \%$ for bolted and welded structures. The Canadian Bridge Standard [50] recommends the use of damping ratio of $0.75 \%$ to $1 \%$ for wind analysis of sign structures and vibration of pedestrian bridges. The code AISC [51] proposes values of $3 \%$ to $5 \%$ for a steel structure under earthquake loading. The Eurocode 1 part 1-4 [52] defining the wind action provides values of structural damping of $0.32 \%$ for welded lattice steel towers, $0.48 \%$ when high strength bolts are used and $0.80 \%$ in the case of ordinary bolts. In the Eurocode 8 part 1-1 [53] for seismic design a damping value of $2 \%$ for welded structures and $4 \%$ for bolted structures is recommended. Overall, there is no general agreement on the value of damping that shall be used in structural 


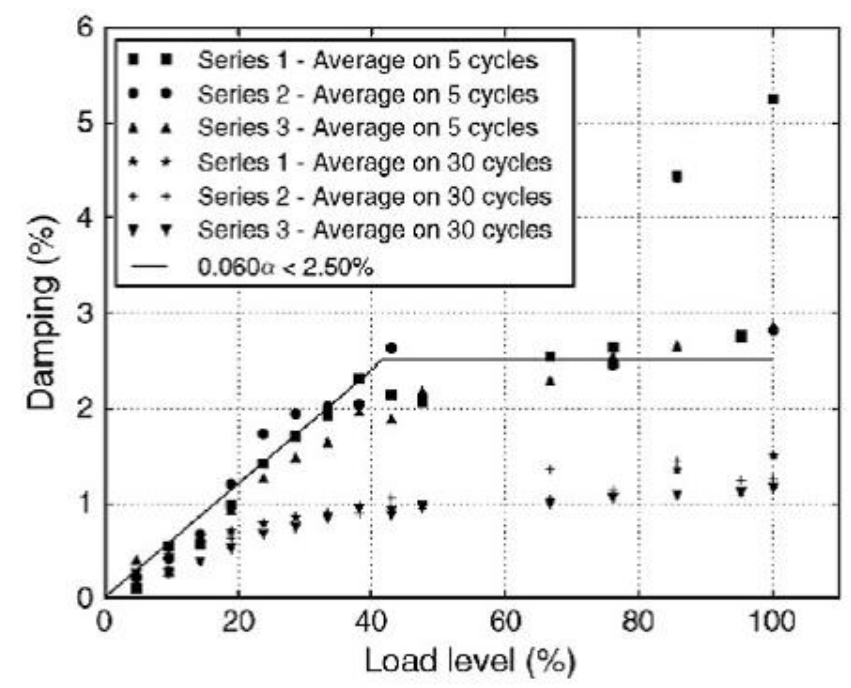

Figure 3.1: Damping ratio average in terms of the \% load level.

design according to the level of stress and there is no guidance on the modelling assumption to be used. This is probably due to the lack of full scale damping and stiffness measurements for lattice towers as observed by Glanville et al. [48].

Experience [54] shows that the structural damping in terms of the logarithmic decrement is usually of the order of $3 \%(\xi \approx 0.48 \%)$ for the blades and of $5 \%(\xi \approx 0.8 \%)$ for the shaft and the tower. Taking to account all matters mentioned above, $0.5 \%$ is adapted for the structural damping in the simulations.

\subsection{Element size}

The running time and accuracy of a boundary element solution are greatly affected by the mesh quality. The major advantage of this method is that only the boundary surface (e.g., the exterior of the vibrating body) needs to be modelled with a mesh of elements. Several recommendations are provided in order to set the element size for wave propagation analyses. The general concept is that the mesh should be fine enough to resolve the propagating wave. Of course, better results should be expected from highly refined models; nevertheless, they are computationally expensive and may be impractical from an engineering point of view. Therefore, a compromise must be reached among discretization quality and solution efficiency.

The dimensions of the square foundation are assumed to be $2 a \times 2 b$ (width $\mathrm{x}$ length). Each layer is characterized by thickness $h(m)$, the shear wave velocity $V_{s}(m / s)$, Poisson's ratio $\nu$, density $\rho_{s}\left(k N / m^{3}\right)$, complex shear modulus $G(M P a)$ and Young's modulus $E(M P a)$.

In order to save some computational cost, mesh sensitivity test will be performed. The geometry of the system considered is massless rigid surface foundation of a base area $2 \mathrm{a} x$ $2 \mathrm{~b}$ in a uniform elastic half-space. The considered data's which are dimensionless, $h=10$, $G=1, \nu=0.3, \rho=1$ and the results are shown in figure 3.2 using "BEASSI".

Taking to account the result, the mesh size is taken as $11 \times 11$, which represents 121 elements and 144 nodes. 

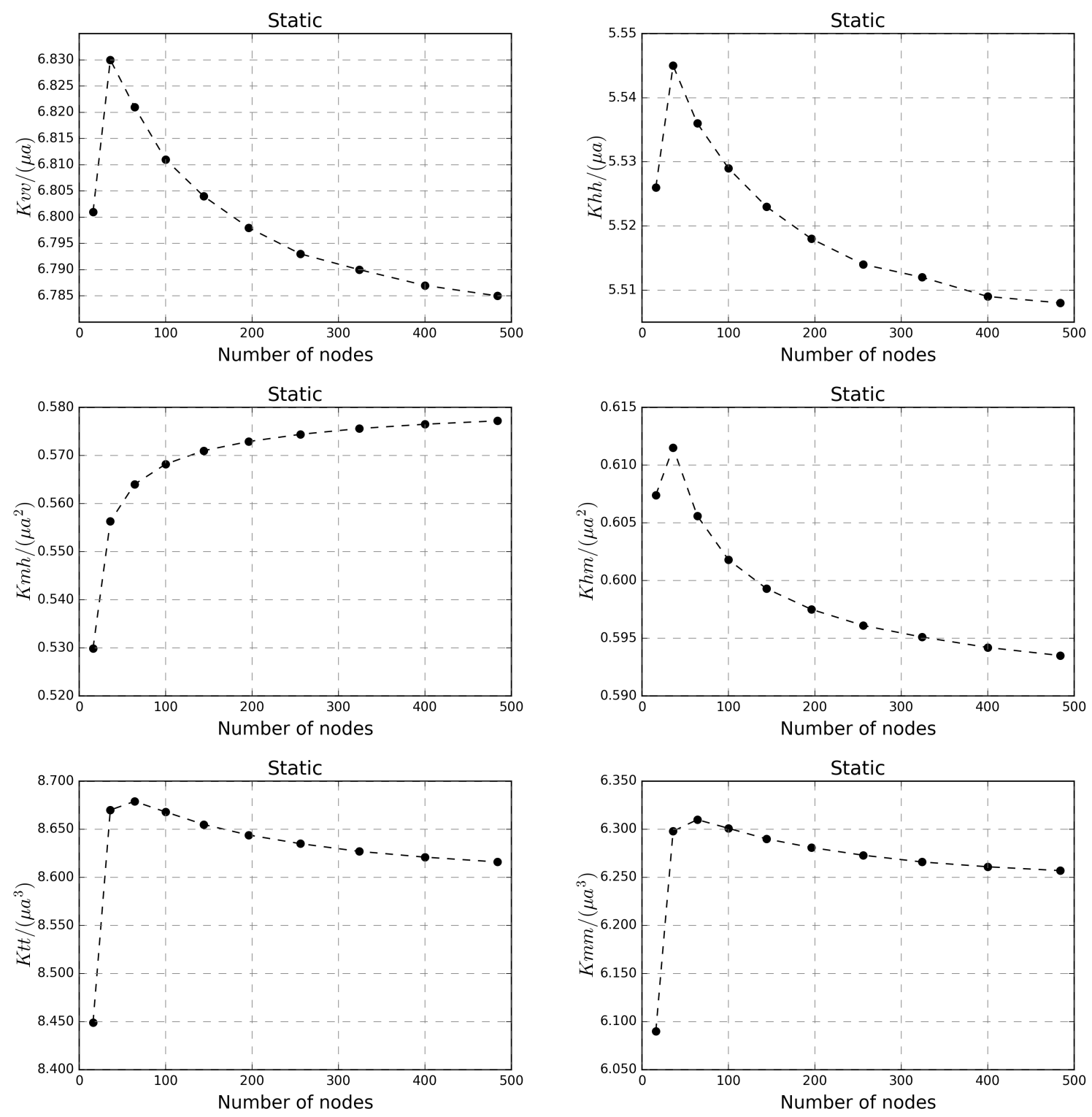

Figure 3.2: Mesh dependency

\subsection{Analytical validation}

An analytical validation is carried out, comparing the simple formulation provided by DNV document [45] in figure 2.3 with the results from "Beassi", choosing the finest mesh size $21 \mathrm{x}$ 21. Considering the same data's given as in section 3.2, table 3.1 shows the obtained data. 


\begin{tabular}{|l|c|c|}
\hline & \multicolumn{2}{|c|}{ Static Case } \\
\hline Mode of vibration & DNV formulation & BEASSI \\
\hline$K_{v v}(\mathrm{kN} / \mathrm{m})$ & 6.448 & 6.785 \\
\hline$K_{h h}(\mathrm{kN} / \mathrm{m})$ & 5.310 & 5.508 \\
\hline$K_{m m}(\mathrm{kN} / \mathrm{rd})$ & 5.473 & 6.257 \\
\hline$K_{t t}(\mathrm{kN} / \mathrm{rd})$ & 7.662 & 8.616 \\
\hline
\end{tabular}

Table 3.1: Comparison between simple formulation provided by DNV from figure 2.3 and "BEASSI"

The result extracted from "BEASSI" has taking into account the mesh of elements, unlike the formulation provided by DNV, and the geometry of foundation marks the difference between the results. 


\section{ChAPTER 4}

\section{Problem statement}

\subsection{Introduction}

The purpose of this section is to display the steps required for calculating the dynamic impedance of foundation on multi-layered soil. To do this, it is important to describe the geometry and structural properties of the foundation, and to combine such a model with the surrounding soil using the displacement compatibility and equilibrium conditions at the interface. There are two basic models that can be used to represent a foundation:

- a rigid body model, which is appropriate for the case of massive foundations and

- flexible foundation model, which the flexibility of the foundation is taken into account.

In this case, the first model of rigid body model will be used due to the dimension of the foundation. For the case of a rigid model of a three-dimensional foundation, the motion of the foundation can be expressed in terms of six components: one vertical, two horizontal, two rocking and one torsional. The soil profile with rigid square foundation is shown in figure 4.1, in which different combinations of soil properties for the multi-layered strata are used. To obtain it, the Young's modulus $E$ of each layer will be increased 10\%, 20\% and $30 \%$.

The gravity based foundation used for this project is a concrete caisson with a dimension of $33 \times 33 \mathrm{~m}$, shown as in figure 4.1 . 


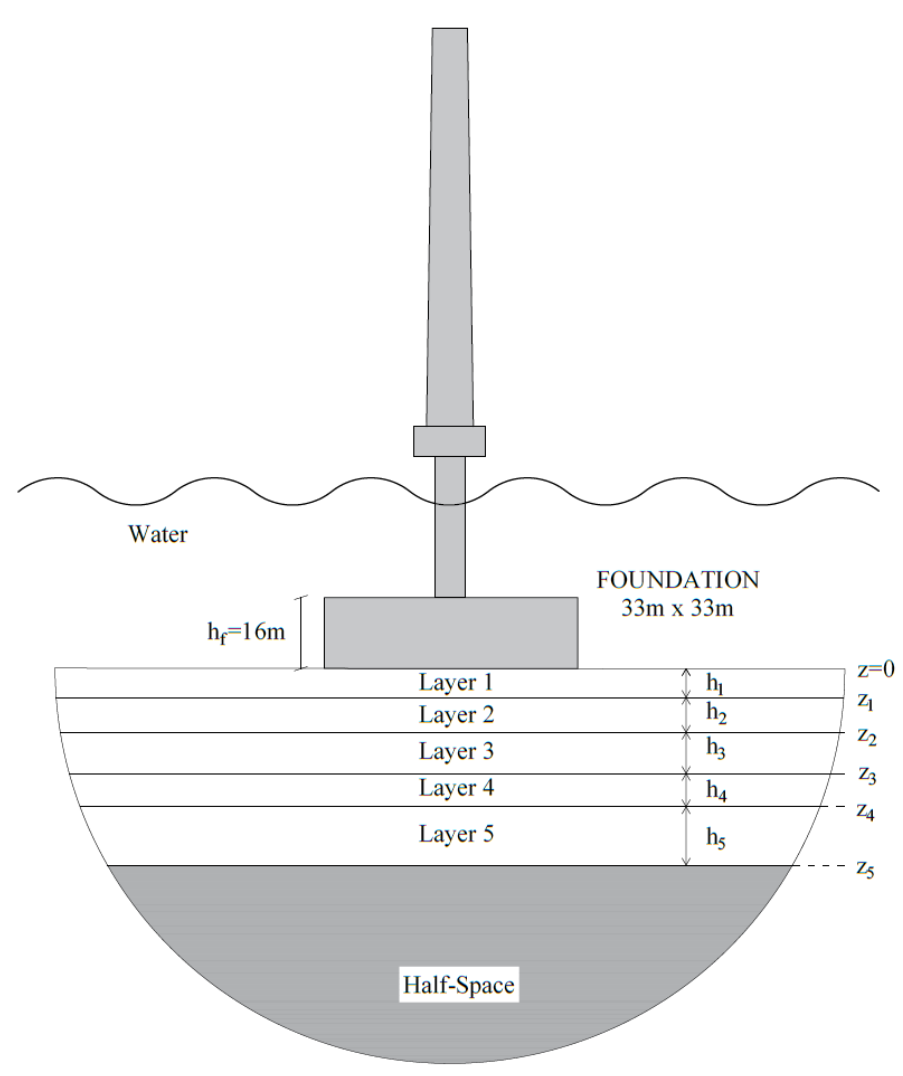

Figure 4.1: A gravity based foundation on a multi-layered soil

Table 4.1 shows the properties of multi-layered soil, it consists of five layers, which is used to analyse and it will be taken as reference strata during the experiment.

\begin{tabular}{|r|ccccccc|l|}
\hline Layer & $h(m)$ & $z(m)$ & $\rho_{s}\left(k N / m^{3}\right)$ & $E(M p a)$ & $\nu$ & $G(M p a)$ & $V_{s}(m / s)$ & Material \\
\hline 1 & 1.5 & 1.5 & 22 & 34.8 & 0.45 & 12 & 73.85 & Berm \\
2 & 3 & 4.5 & 18 & 17.4 & 0.45 & 6 & 57.74 & Surface sediments \\
3 & 2 & 6.5 & 21 & 58 & 0.45 & 20 & 97.59 & Rewoked till \\
4 & 3 & 9.5 & 22 & 174 & 0.45 & 60 & 165.14 & Over Consolidated till \\
5 & 3 & 12.5 & 18 & 43.5 & 0.45 & 15 & 91.29 & Lower cretaceous \\
\hline
\end{tabular}

Table 4.1: Properties of multi-layered soil

With regards to the above mentioned data's, the concrete foundation is designed and analysed in the Boundary Element Analysis for Soil-Structure Interaction "Beassi". The purpose of this analysis is to obtain the dynamic stiffness results for vertical $\left(K_{v v}\right)$, horizontal $\left(K_{h h}\right)$, rocking $\left(K_{m m}\right)$ and torsion $\left(K_{t t}\right)$ for different half-space configurations increasing each layers Young's modulus 10\%, 20\% and 30\%. The foundation is fully-contact to the layered half-space through a $1.5 \mathrm{~m}$ thickness berm with stone and protection material and is meshed 
by $11 \times 11$ four nodded singular elements. In table 4.2 shows the dynamic stiffness for vertical $\left(K_{v v}\right)$, horizontal $\left(K_{h h}\right)$, rocking $\left(K_{m m}\right)$ and torsion $\left(K_{t t}\right)$ which is calculated by "BEASSI", from periods $0.5 \mathrm{~s}$ to $10 \mathrm{~s}$. To simplify the experiment, only excitation period of $2 \mathrm{~s}$ will be taken into account to run the simulations to compare the results.

\begin{tabular}{|c|c|c|c|c|c|c|c|c|}
\hline & \multicolumn{2}{|c|}{$K_{v v}(\mathrm{kN} / \mathrm{m})$} & \multicolumn{2}{|c|}{$K_{h h}(\mathrm{kN} / \mathrm{m})$} & \multicolumn{2}{|c|}{$K_{m m}(\mathrm{kN} / \mathrm{rd})$} & \multicolumn{2}{|c|}{$K_{t t}(\mathrm{kN} / \mathrm{rd})$} \\
\hline $\mathrm{T}(\mathrm{s})$ & Re & $\operatorname{Im}$ & $\operatorname{Re}$ & $\operatorname{Im}$ & $\operatorname{Re}$ & $\operatorname{Im}$ & Re & $\operatorname{Im}$ \\
\hline 0.5 & $9.9495 \mathrm{E}+05$ & $5.8836 \mathrm{E}+06$ & $1.1920 \mathrm{E}+06$ & $1.2890 \mathrm{E}+06$ & $3.3179 \mathrm{E}+08$ & $3.6764 \mathrm{E}+08$ & $2.7546 \mathrm{E}+08$ & $1.8508 \mathrm{E}+08$ \\
\hline 1 & $1.5543 \mathrm{E}+06$ & $2.5146 \mathrm{E}+06$ & $1.3355 \mathrm{E}+06$ & $7.5488 \mathrm{E}+05$ & $3.7788 \mathrm{E}+08$ & $1.3390 \mathrm{E}+08$ & $3.9055 \mathrm{E}+08$ & $6.3959 \mathrm{E}+07$ \\
\hline 1.5 & $1.7810 \mathrm{E}+06$ & $1.6117 \mathrm{E}+06$ & $1.3474 \mathrm{E}+06$ & $5.3846 \mathrm{E}+05$ & $4.1669 \mathrm{E}+08$ & $6.7571 \mathrm{E}+07$ & $4.2424 \mathrm{E}+08$ & $3.7033 \mathrm{E}+07$ \\
\hline 2 & $1.8800 \mathrm{E}+06$ & $1.1989 \mathrm{E}+06$ & $1.3484 \mathrm{E}+06$ & $4.2580 \mathrm{E}+05$ & $4.3960 \mathrm{E}+08$ & $4.3070 \mathrm{E}+07$ & $4.3933 \mathrm{E}+08$ & $2.7761 \mathrm{E}+07$ \\
\hline 2.5 & $1.9315 \mathrm{E}+06$ & $9.6179 \mathrm{E}+05$ & $1.3474 \mathrm{E}+06$ & $3.5670 \mathrm{E}+05$ & $4.5335 \mathrm{E}+08$ & $3.2451 \mathrm{E}+07$ & $4.4715 \mathrm{E}+08$ & $2.3778 \mathrm{E}+07$ \\
\hline 3 & $1.9622 \mathrm{E}+06$ & $8.0834 \mathrm{E}+05$ & $1.3464 \mathrm{E}+06$ & $3.0967 \mathrm{E}+05$ & $4.6197 \mathrm{E}+08$ & $2.7276 \mathrm{E}+07$ & $4.5173 \mathrm{E}+08$ & $2.1791 \mathrm{E}+07$ \\
\hline 4 & $1.9949 \mathrm{E}+06$ & $6.2093 \mathrm{E}+05$ & $1.3434 \mathrm{E}+06$ & $2.4978 \mathrm{E}+05$ & $4.7113 \mathrm{E}+08$ & $2.2842 \mathrm{E}+07$ & $4.5658 \mathrm{E}+08$ & $2.0042 \mathrm{E}+07$ \\
\hline 5 & $2.0107 \mathrm{E}+06$ & $5.1064 \mathrm{E}+05$ & $1.3405 \mathrm{E}+06$ & $2.1285 \mathrm{E}+05$ & $4.7599 \mathrm{E}+08$ & $2.1188 \mathrm{E}+07$ & $4.5901 \mathrm{E}+08$ & $1.9355 \mathrm{E}+07$ \\
\hline 6 & $2.0206 \mathrm{E}+06$ & $4.3798 \mathrm{E}+05$ & $1.3395 \mathrm{E}+06$ & $1.8790 \mathrm{E}+05$ & $4.7841 \mathrm{E}+08$ & $2.0438 \mathrm{E}+07$ & $4.6035 \mathrm{E}+08$ & $1.9034 \mathrm{E}+07$ \\
\hline 8 & $2.0305 \mathrm{E}+06$ & $3.4799 \mathrm{E}+05$ & $1.3375 \mathrm{E}+06$ & $1.5593 \mathrm{E}+05$ & $4.8111 \mathrm{E}+08$ & $1.9837 \mathrm{E}+07$ & $4.6197 \mathrm{E}+08$ & $1.8765 \mathrm{E}+07$ \\
\hline 10 & $2.0354 \mathrm{E}+06$ & $2.9433 \mathrm{E}+05$ & $1.3355 \mathrm{E}+06$ & $1.3632 \mathrm{E}+05$ & $4.8245 \mathrm{E}+08$ & $1.9622 \mathrm{E}+07$ & $4.6251 \mathrm{E}+08$ & $1.8662 \mathrm{E}+07$ \\
\hline
\end{tabular}

Table 4.2: Dynamic stiffness on five layered strata(reference strata)

\subsection{Dynamic stiffness using 3D boundary element program BEASSI}

Next sub-chapters presents the variations in the dynamic stiffness considering different values of Young's modulus. This analysis is made in order to show the influence of multi-layered strata on the SSI effect.

\subsubsection{Variation of Young's modulus 10\%}

The proceeding consist in increasing ten percent the Young's modulus of each one of the layers. In other words, the Young's modulus of layer one is increased $10 \%$ leaving the rest of the layers without changes and so on till layer five. To get an idea, dynamic stiffness of reference strata is also shown in the table 4.3. 


\begin{tabular}{|l|c|c|c|c|c|c|c|c|}
\hline $\mathrm{T}=2 \mathrm{~s}$ & \multicolumn{2}{|c|}{$K_{v v}(\mathrm{kN} / \mathrm{m})$} & \multicolumn{2}{c|}{$K_{h h}(\mathrm{kN} / \mathrm{m})$} & \multicolumn{2}{c|}{$K_{m m}(\mathrm{kN} / \mathrm{rd})$} & \multicolumn{2}{c|}{$K_{t t}(\mathrm{kN} / \mathrm{rd})$} \\
\hline Layers & $\operatorname{Re}$ & $\mathrm{Im}$ & $\mathrm{Re}$ & $\mathrm{Im}$ & $\mathrm{Re}$ & $\mathrm{Im}$ & $\mathrm{Re}$ & $\mathrm{Im}$ \\
\hline Ref. & $1.8800 \mathrm{E}+06$ & $1.1989 \mathrm{E}+06$ & $1.3484 \mathrm{E}+06$ & $4.2580 \mathrm{E}+05$ & $4.3960 \mathrm{E}+08$ & $4.3070 \mathrm{E}+07$ & $4.3933 \mathrm{E}+08$ & $2.7761 \mathrm{E}+07$ \\
\hline 1 & $1,8879 \mathrm{E}+06$ & $1,2078 \mathrm{E}+06$ & $1,3820 \mathrm{E}+06$ & $4,4382 \mathrm{E}+05$ & $4,4499 \mathrm{E}+08$ & $4,3798 \mathrm{E}+07$ & $4,5712 \mathrm{E}+08$ & $2,9190 \mathrm{E}+07$ \\
\hline 2 & $1,8981 \mathrm{E}+06$ & $1,2251 \mathrm{E}+06$ & $1,3885 \mathrm{E}+06$ & $4,4791 \mathrm{E}+05$ & $4,5154 \mathrm{E}+08$ & $4,4769 \mathrm{E}+07$ & $4,5510 \mathrm{E}+08$ & $2,9014 \mathrm{E}+07$ \\
\hline 3 & $1,8840 \mathrm{E}+06$ & $1,2058 \mathrm{E}+06$ & $1,3593 \mathrm{E}+06$ & $4,2847 \mathrm{E}+05$ & $4,4283 \mathrm{E}+08$ & $4,3529 \mathrm{E}+07$ & $4,4229 \mathrm{E}+08$ & $2,7896 \mathrm{E}+07$ \\
\hline 4 & $1,8830 \mathrm{E}+06$ & $1,2078 \mathrm{E}+06$ & $1,3682 \mathrm{E}+06$ & $4,2303 \mathrm{E}+05$ & $4,4283 \mathrm{E}+08$ & $4,3583 \mathrm{E}+07$ & $4,4337 \mathrm{E}+08$ & $2,7546 \mathrm{E}+07$ \\
\hline 5 & $1,8889 \mathrm{E}+06$ & $1,2098 \mathrm{E}+06$ & $1,3553 \mathrm{E}+06$ & $4,2639 \mathrm{E}+05$ & $4,4337 \mathrm{E}+08$ & $4,3529 \mathrm{E}+07$ & $4,4041 \mathrm{E}+08$ & $2,7734 \mathrm{E}+07$ \\
\hline
\end{tabular}

Table 4.3: Dynamic stiffness after increasing Young's modulus of each layer 10\%

\subsubsection{Variation of Young's modulus 20\%}

Table 4.4 shows the results of dynamic stiffness after increasing Young's modulus $20 \%$.

\begin{tabular}{|l|c|c|c|c|c|c|c|c|}
\hline \multirow{2}{*}{$\mathrm{T}=2 \mathrm{~s}$} & \multicolumn{2}{|c|}{$K_{v v}(\mathrm{kN} / \mathrm{m})$} & \multicolumn{2}{c|}{$K_{h h}(\mathrm{kN} / \mathrm{m})$} & \multicolumn{2}{c|}{$K_{m m}(\mathrm{kN} / \mathrm{rd})$} & \multicolumn{2}{c|}{$K_{t t}(\mathrm{kN} / \mathrm{rd})$} \\
\hline Layers & $\operatorname{Re}$ & $\mathrm{Im}$ & $\operatorname{Re}$ & $\operatorname{Im}$ & $\operatorname{Re}$ & $\operatorname{Im}$ & $\operatorname{Re}$ & $\operatorname{Im}$ \\
\hline Ref. & $1.8800 \mathrm{E}+06$ & $1.1989 \mathrm{E}+06$ & $1.3484 \mathrm{E}+06$ & $4.2580 \mathrm{E}+05$ & $4.3960 \mathrm{E}+08$ & $4.3070 \mathrm{E}+07$ & $4.3933 \mathrm{E}+08$ & $2.7761 \mathrm{E}+07$ \\
\hline 1 & $1,8949 \mathrm{E}+06$ & $1,2167 \mathrm{E}+06$ & $1,4127 \mathrm{E}+06$ & $4,6065 \mathrm{E}+05$ & $4,4957 \mathrm{E}+08$ & $4,4445 \mathrm{E}+07$ & $4,7383 \mathrm{E}+08$ & $3,0564 \mathrm{E}+07$ \\
\hline 2 & $1,9127 \mathrm{E}+06$ & $1,2486 \mathrm{E}+06$ & $1,4256 \mathrm{E}+06$ & $4,6843 \mathrm{E}+05$ & $4,6251 \mathrm{E}+08$ & $4,6348 \mathrm{E}+07$ & $4,6995 \mathrm{E}+08$ & $3,0173 \mathrm{E}+07$ \\
\hline 3 & $1,8879 \mathrm{E}+06$ & $1,2118 \mathrm{E}+06$ & $1,3692 \mathrm{E}+06$ & $4,3055 \mathrm{E}+05$ & $4,4580 \mathrm{E}+08$ & $4,3933 \mathrm{E}+07$ & $4,4526 \mathrm{E}+08$ & $2,7977 \mathrm{E}+07$ \\
\hline 4 & $1,8860 \mathrm{E}+06$ & $1,2167 \mathrm{E}+06$ & $1,3860 \mathrm{E}+06$ & $4,2006 \mathrm{E}+05$ & $4,4580 \mathrm{E}+08$ & $4,4068 \mathrm{E}+07$ & $4,4688 \mathrm{E}+08$ & $2,7330 \mathrm{E}+07$ \\
\hline 5 & $1,8968 \mathrm{E}+06$ & $1,2197 \mathrm{E}+06$ & $1,3613 \mathrm{E}+06$ & $4,2669 \mathrm{E}+05$ & $4,4661 \mathrm{E}+08$ & $4,3960 \mathrm{E}+07$ & $4,4149 \mathrm{E}+08$ & $2,7707 \mathrm{E}+07$ \\
\hline
\end{tabular}

Table 4.4: Dynamic stiffness after increasing Young's modulus of each layer 20\%

\subsubsection{Variation of Young's modulus 30\%}

Table 4.5 shows the results of dynamic stiffness after increasing Young's modulus $30 \%$.

\begin{tabular}{|l|c|c|c|c|c|c|c|c|}
\hline $\mathrm{T}=2 \mathrm{~s}$ & \multicolumn{2}{|c|}{$K_{v v}(\mathrm{kN} / \mathrm{m})$} & \multicolumn{2}{c|}{$K_{h h}(\mathrm{kN} / \mathrm{m})$} & \multicolumn{2}{c|}{$K_{m m}(\mathrm{kN} / \mathrm{rd})$} & \multicolumn{2}{c|}{$K_{t t}(\mathrm{kN} / \mathrm{rd})$} \\
\hline Layers & $\operatorname{Re}$ & $\operatorname{Im}$ & $\mathrm{Re}$ & $\mathrm{Im}$ & $\operatorname{Re}$ & $\operatorname{Im}$ & $\operatorname{Re}$ & $\operatorname{Im}$ \\
\hline Ref. & $1.8800 \mathrm{E}+06$ & $1.1989 \mathrm{E}+06$ & $1.3484 \mathrm{E}+06$ & $4.2580 \mathrm{E}+05$ & $4.3960 \mathrm{E}+08$ & $4.3070 \mathrm{E}+07$ & $4.3933 \mathrm{E}+08$ & $2.7761 \mathrm{E}+07$ \\
\hline 1 & $1,9008 \mathrm{E}+06$ & $1,2246 \mathrm{E}+06$ & $1,4414 \mathrm{E}+06$ & $4,7669 \mathrm{E}+05$ & $4,5388 \mathrm{E}+08$ & $4,5065 \mathrm{E}+07$ & $4,9000 \mathrm{E}+08$ & $3,1885 \mathrm{E}+07$ \\
\hline 2 & $1,9254 \mathrm{E}+06$ & $1,2689 \mathrm{E}+06$ & $1,4582 \mathrm{E}+06$ & $4,8700 \mathrm{E}+05$ & $4,7197 \mathrm{E}+08$ & $4,7758 \mathrm{E}+07$ & $4,8353 \mathrm{E}+08$ & $3,1251 \mathrm{E}+07$ \\
\hline 3 & $1,8909 \mathrm{E}+06$ & $1,2167 \mathrm{E}+06$ & $1,3781 \mathrm{E}+06$ & $4,3233 \mathrm{E}+05$ & $4,4822 \mathrm{E}+08$ & $4,4283 \mathrm{E}+07$ & $4,4769 \mathrm{E}+08$ & $2,8031 \mathrm{E}+07$ \\
\hline 4 & $1,8879 \mathrm{E}+06$ & $1,2246 \mathrm{E}+06$ & $1,4028 \mathrm{E}+06$ & $4,1709 \mathrm{E}+05$ & $4,4849 \mathrm{E}+08$ & $4,4499 \mathrm{E}+07$ & $4,5038 \mathrm{E}+08$ & $2,7114 \mathrm{E}+07$ \\
\hline 5 & $1,9028 \mathrm{E}+06$ & $1,2286 \mathrm{E}+06$ & $1,3672 \mathrm{E}+06$ & $4,2689 \mathrm{E}+05$ & $4,4984 \mathrm{E}+08$ & $4,4364 \mathrm{E}+07$ & $4,4256 \mathrm{E}+08$ & $2,7654 \mathrm{E}+07$ \\
\hline
\end{tabular}

Table 4.5: Dynamic stiffness after increasing Young's modulus of each layer 30\% 
Attending to the results, the layer two is found to play a significant role related to the dynamic stiffness. The magnitude of the stiffness functions tend to increase when the mean Young's modulus of the soil profile increases, with the exception of the vertical mode, for which normalized impedance functions are largely independent of the soil profile.

\subsection{Coupled model}

A fully-coupled model of the system in which the lattice tower, the deck, the mono-pile and concrete caisson foundation has been developed as shown in figure 4.2. The data's of the model is based on two real projects, Moray Firth and Inch Cape Mast for EDP and REPSOL, and was provided by my advisor.

The Figure 4.3 shows the general configuration and the links used in "SAP2000" to connect the rigid body mass (with mass and rotational inertial properties, considering concrete and water fractions), and the soil (modelled by springs and dampers). The foundation is analysed when placed at an embedment depth of $1.5 \mathrm{~m}$. With dimensionless quantities $K_{v v}, K_{h h}, K_{m m}$ and $K_{t t}$ obtained from the "BEASSI", after passing it to dimensional quantities, it is possible to run simulations to show the effect of SSI on the wind turbine system with "SAP2000".

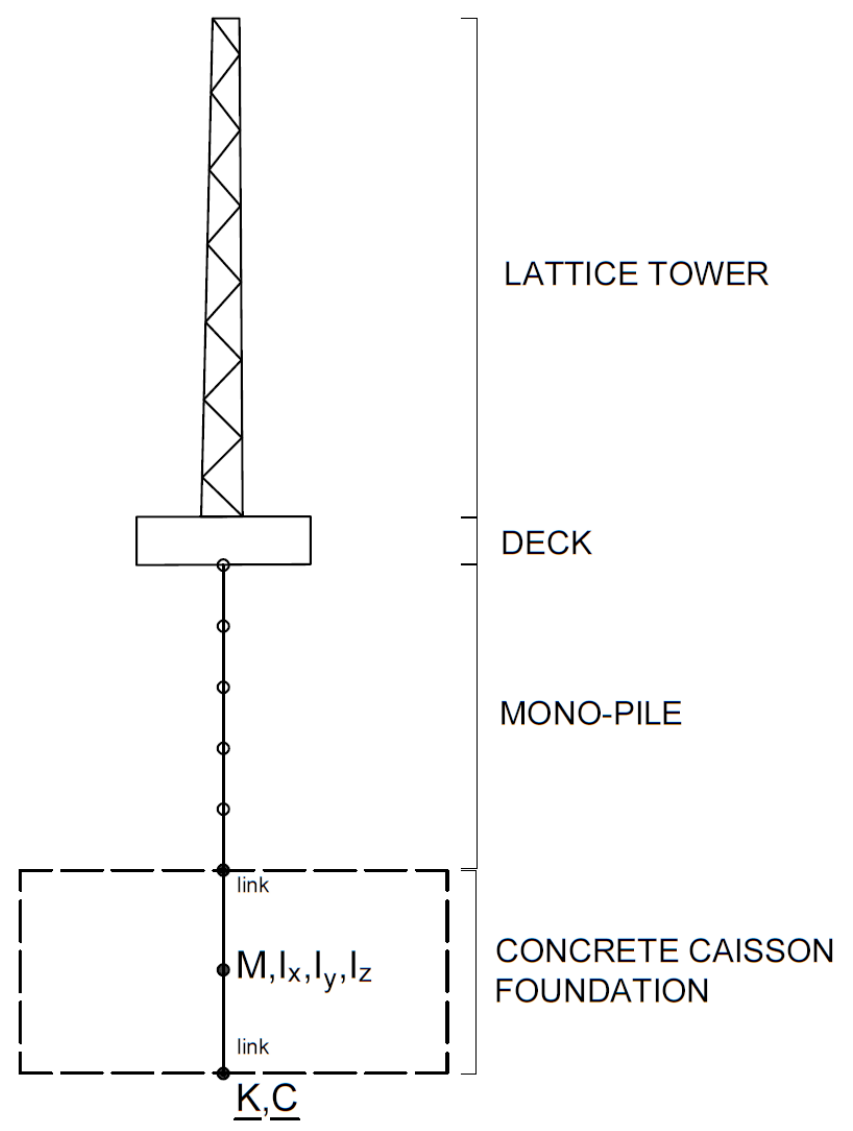

Figure 4.2: Schematic model of an offshore wind turbine for SAP2000 


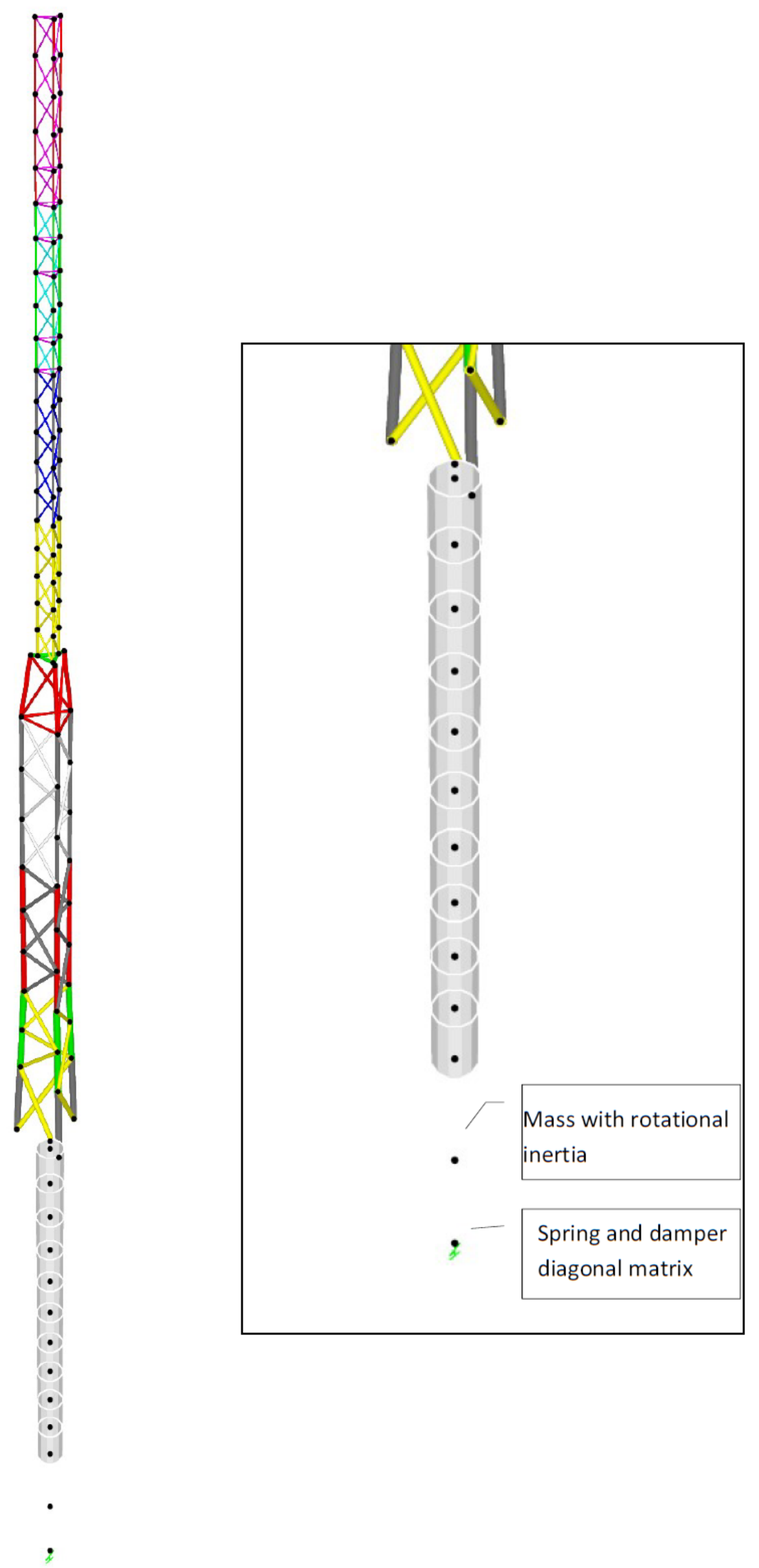

Figure 4.3: Coupled model SAP2000 


\begin{tabular}{|l|c|}
\hline Parameter & Value \\
\hline Mass of the rigid foundation $($ Ton $)$ & 22941 \\
Mass inertia moment X $\left(\right.$ Ton $\left.\cdot m^{4}\right)$ & 2742311 \\
Mass inertia moment Y $\left(\right.$ Ton $\left.\cdot m^{4}\right)$ & 2574724 \\
Mass inertia moment Z $\left(\right.$ Ton $\left.\cdot m^{4}\right)$ & 4195514 \\
\hline
\end{tabular}

Table 4.6: Mass parameters for SSI

To test the effects of damping in the structure, a free vibration test is carried out. A horizontal force of $20 \mathrm{kN}$ is given in X-direction at the top, and it is released, causing free vibration at the structure.

The damper at the foundation is considered with different damping rates at each mode. The rocky rotation at each mode defines the additional damping rate passed to each mode. "SAP2000" computes each modal damping rate. For each mode, $0.5 \%$ damping rate is considered, as structural damping.

Figures 4.4 and 4.5 is the result of SSI effect without bringing any modification to the multi-layered soil, and figures from 4.6-4.35, shows the results when the SSI effect is included increasing Young's modulus, $G$ of each layer 10\%, $20 \%$ and $30 \%$.

In displacements, according to the results below, produces low reductions. This is due to the fact that displacements are affected by the first modes. On the contrary, for accelerations produces great reductions with stronger action on the higher modes.

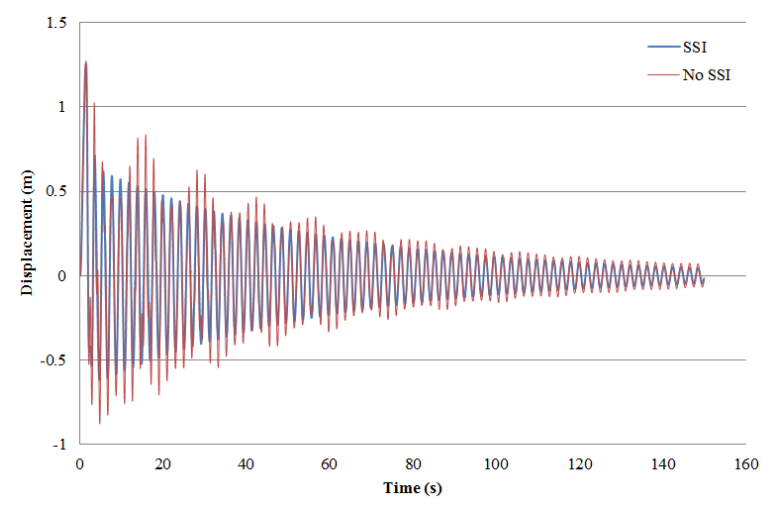

Figure 4.4: Reference Displacement

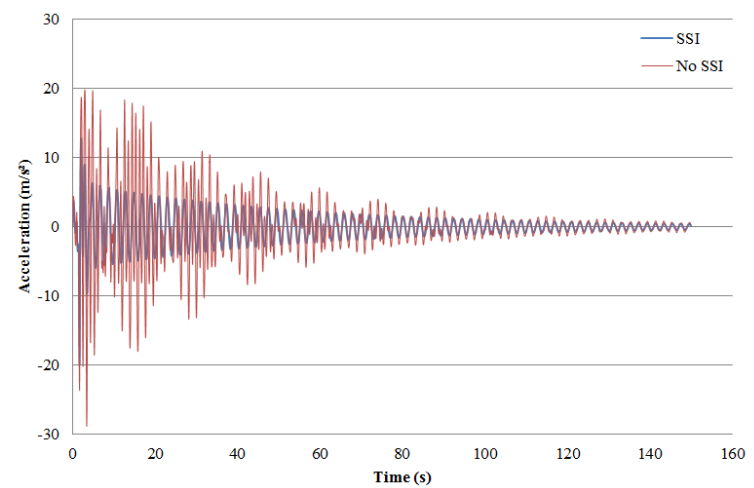

Figure 4.5: Reference Acceleration 


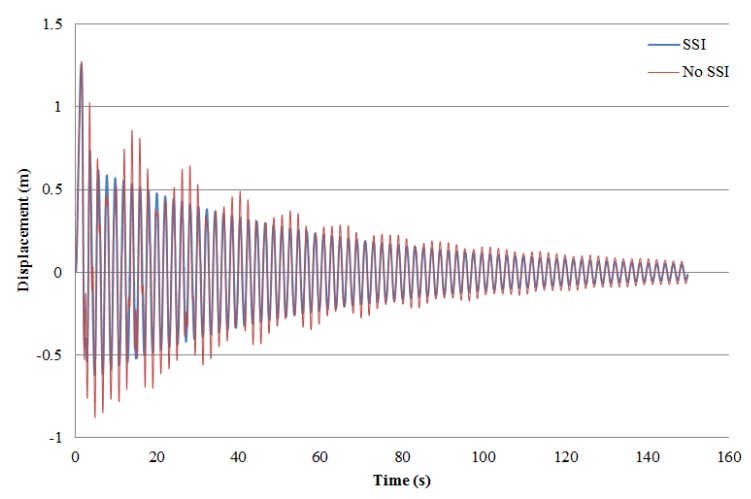

Figure 4.6: Displacement layer 1-10\%

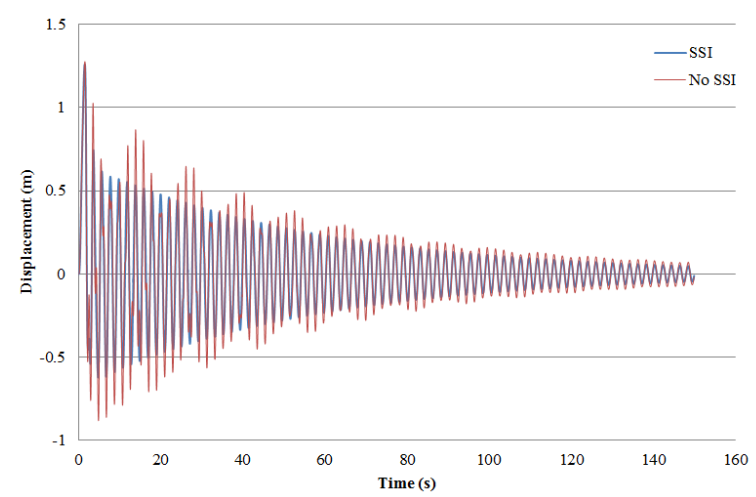

Figure 4.8: Displacement layer 2-10\%

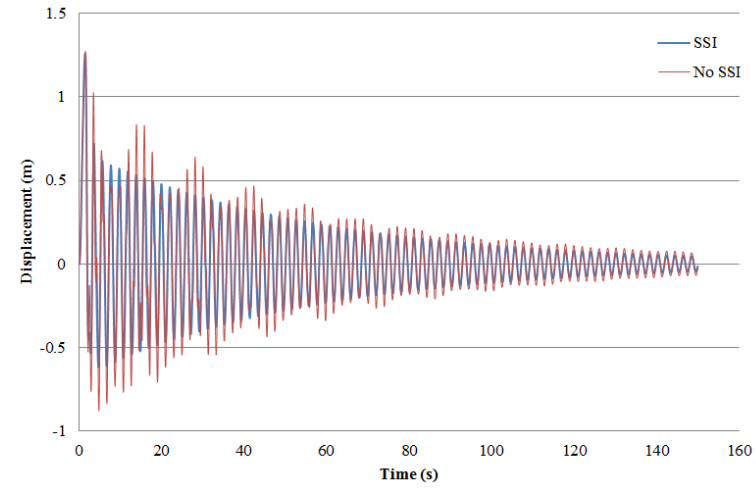

Figure 4.10: Displacement layer 3-10\%

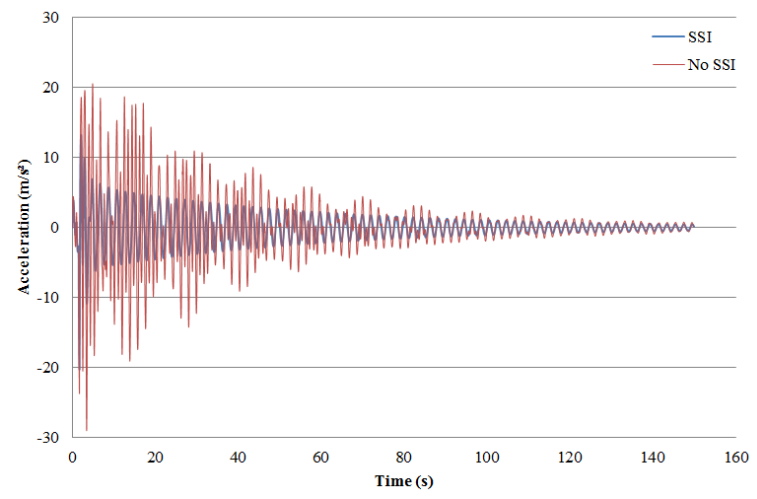

Figure 4.7: Acceleration Layer 1-10\%

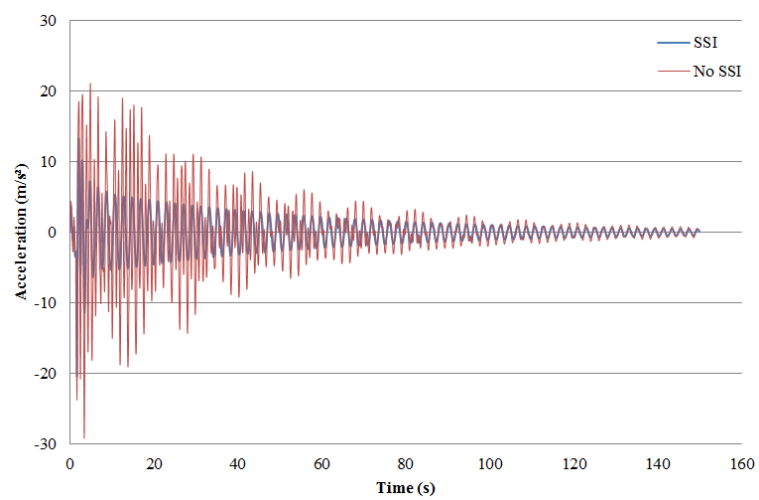

Figure 4.9: Acceleration Layer 2-10\%

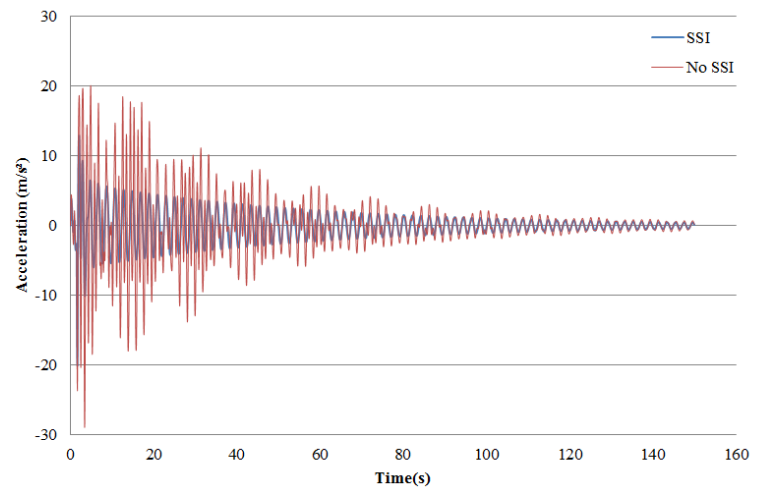

Figure 4.11: Acceleration Layer 3-10\% 


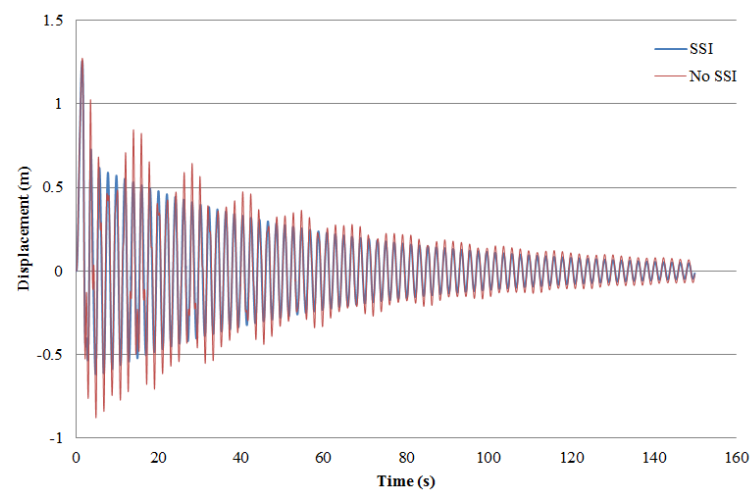

Figure 4.12: Displacement layer 4-10\%

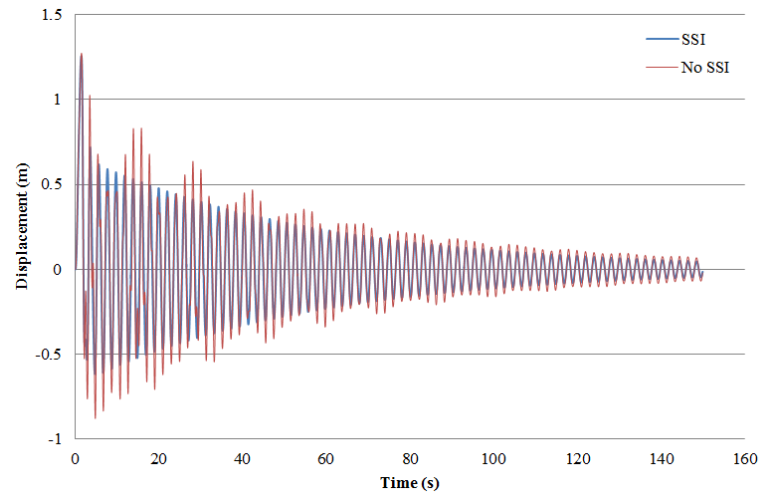

Figure 4.14: Displacement layer 5-10\%

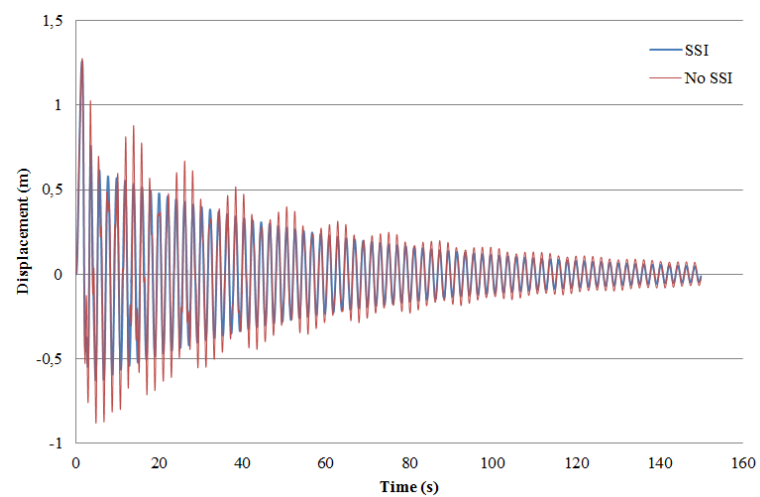

Figure 4.16: Displacement layer 1-20\%

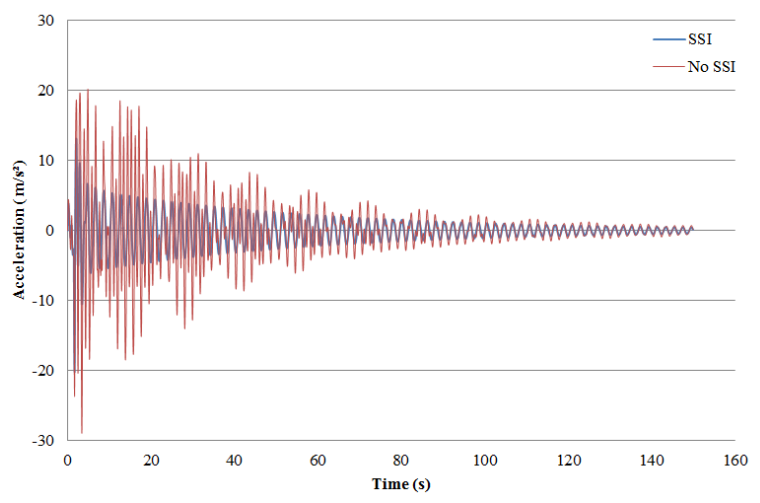

Figure 4.13: Acceleration Layer 4-10\%

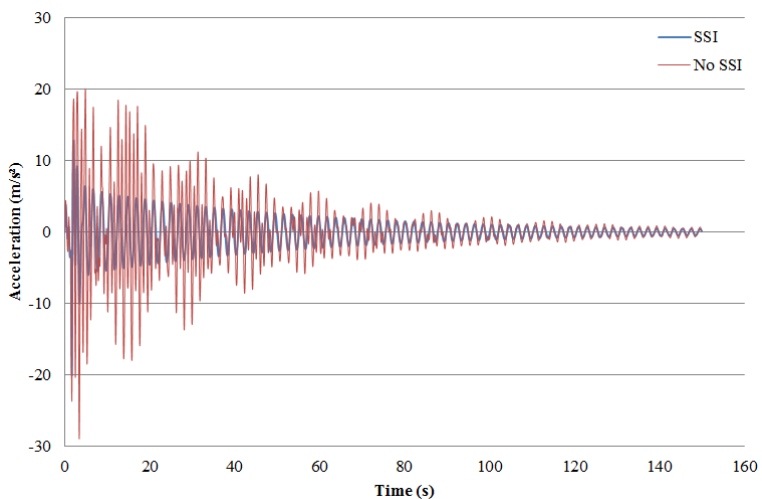

Figure 4.15: Acceleration Layer 5-10\%

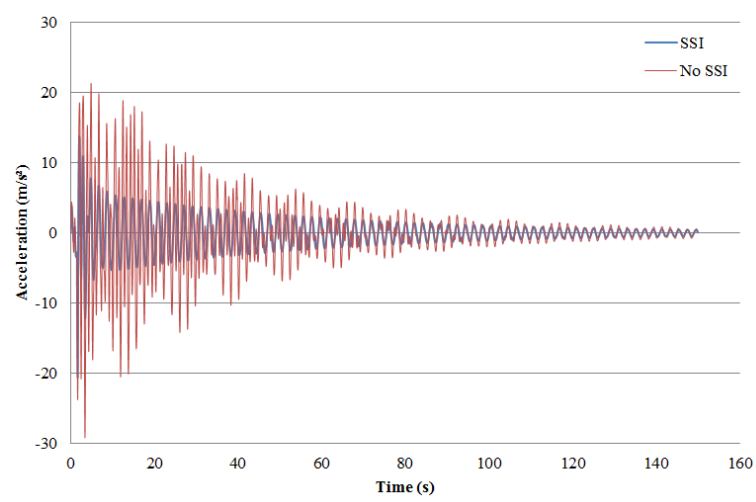

Figure 4.17: Acceleration Layer 1-20\% 


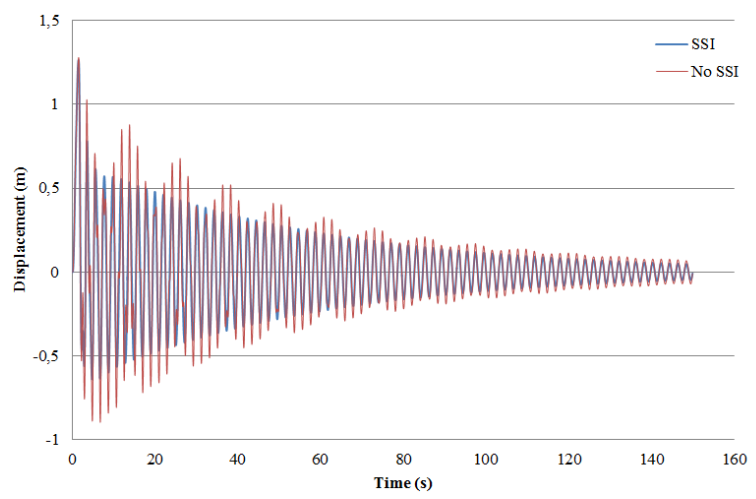

Figure 4.18: Displacement layer 2-20\%

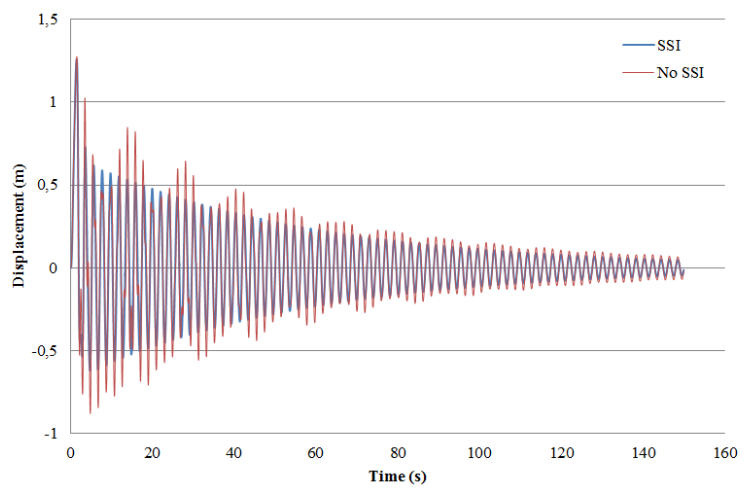

Figure 4.20: Displacement layer 3-20\%

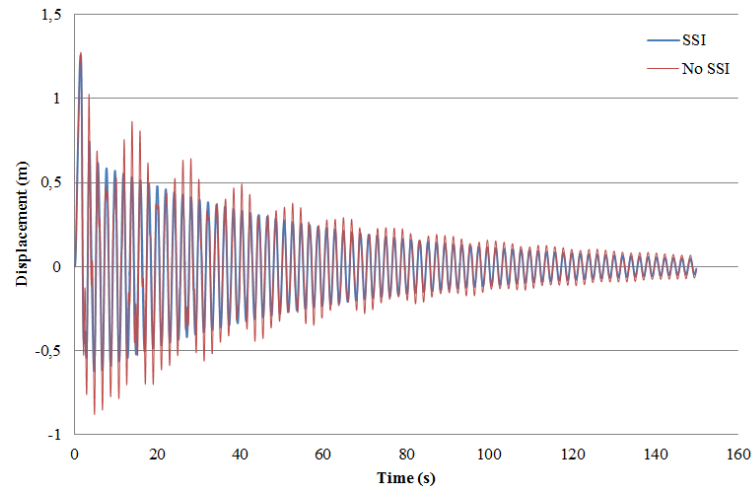

Figure 4.22: Displacement layer 4-20\%

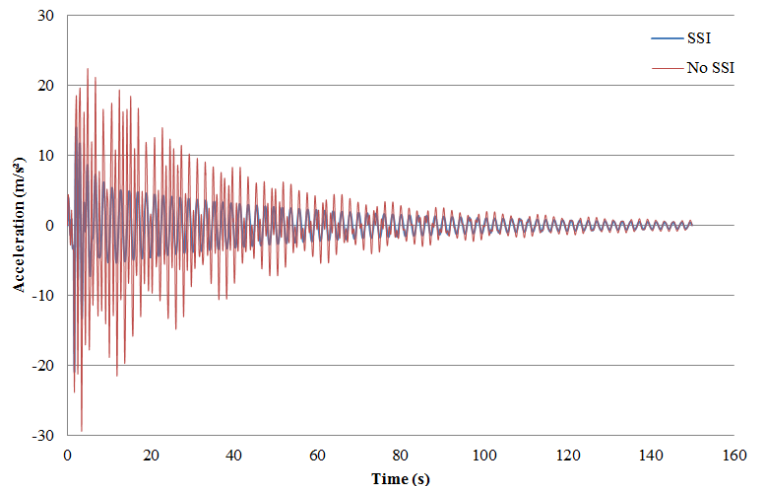

Figure 4.19: Acceleration Layer 2-20\%

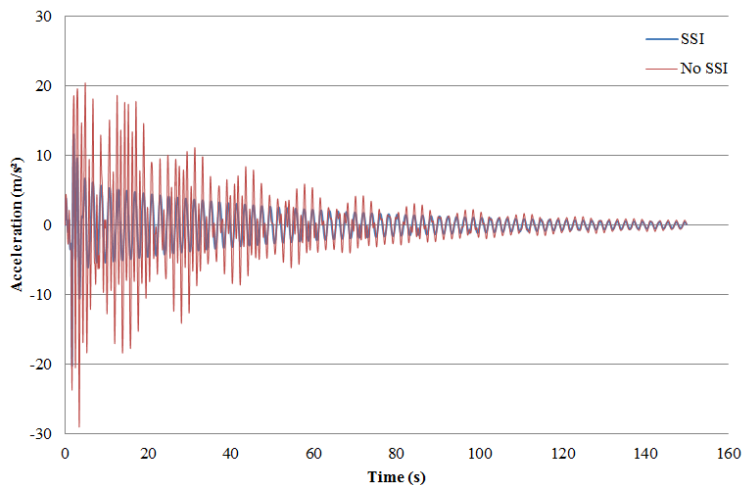

Figure 4.21: Acceleration Layer 3-20\%

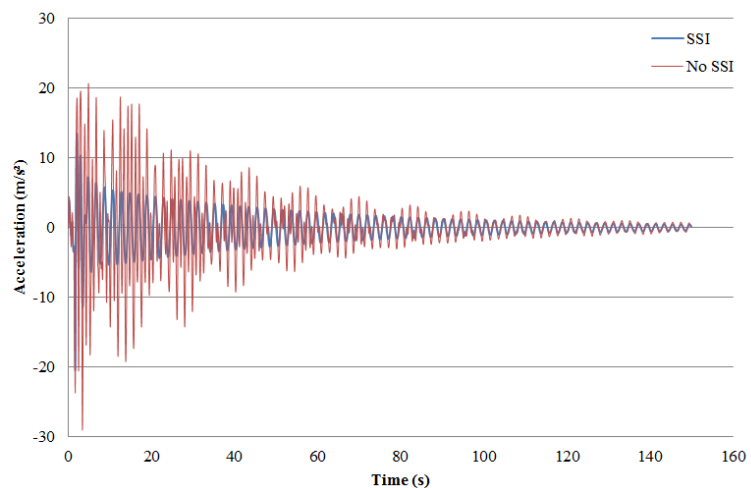

Figure 4.23: Acceleration Layer 4-20\% 


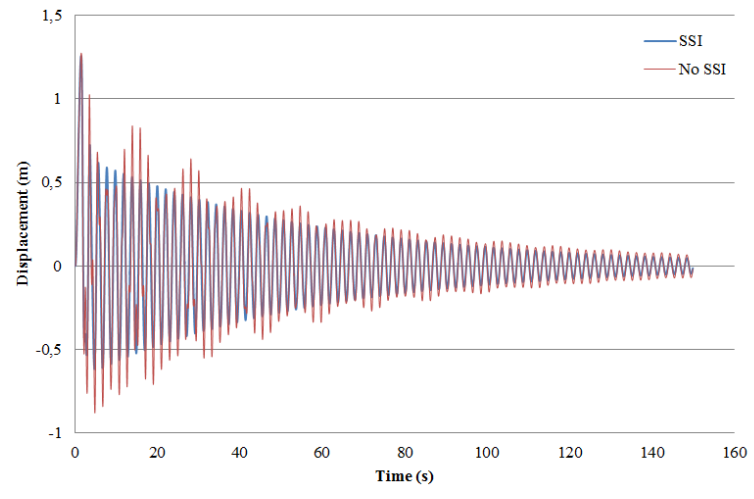

Figure 4.24: Displacement layer 5-20\%

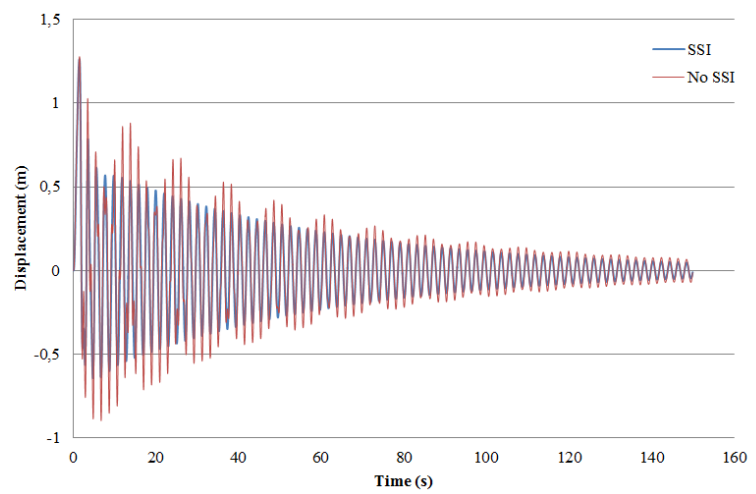

Figure 4.26: Displacement layer 1-30\%

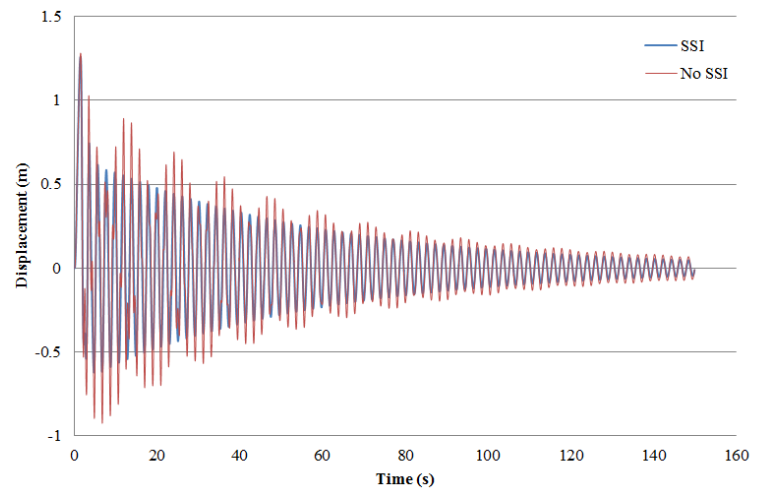

Figure 4.28: Displacement layer 2-30\%

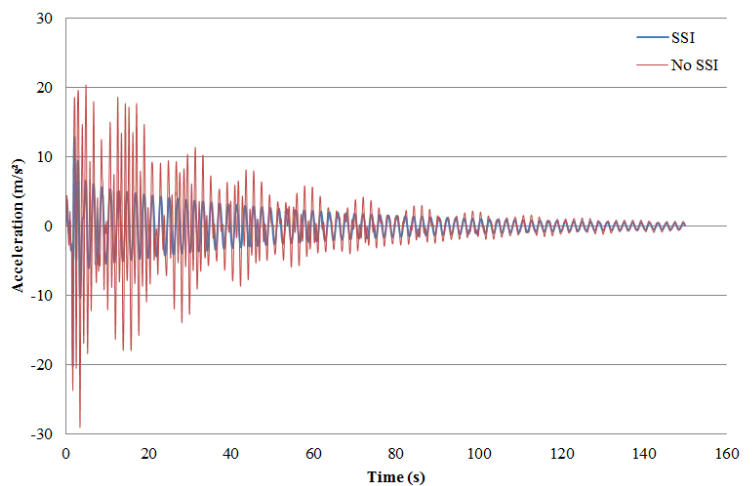

Figure 4.25: Acceleration Layer 5-20\%

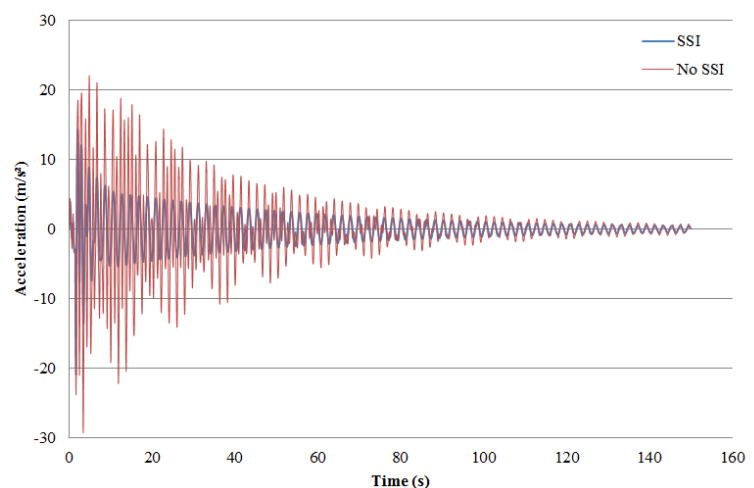

Figure 4.27: Acceleration Layer 1-30\%

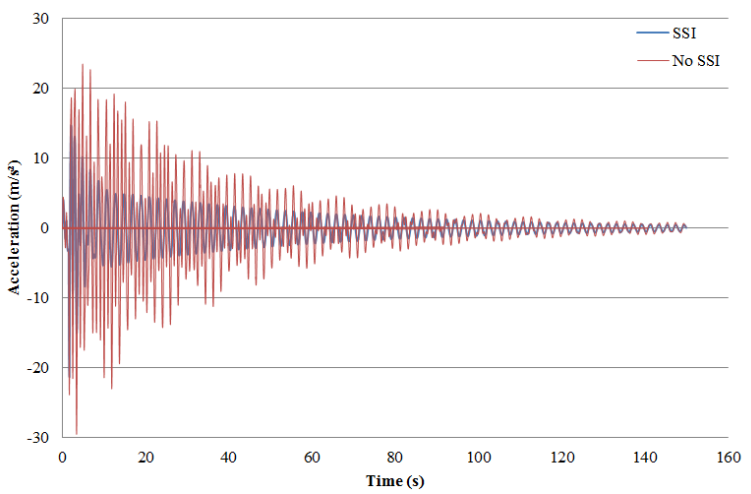

Figure 4.29: Acceleration Layer 2-30\% 


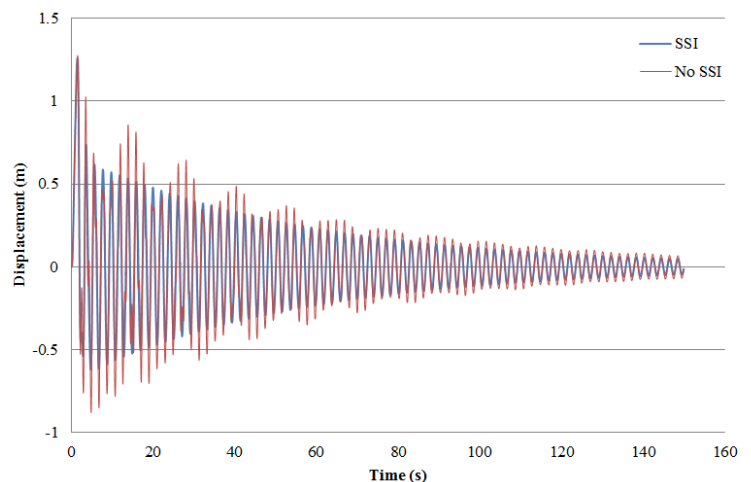

Figure 4.30: Displacement layer 3-30\%

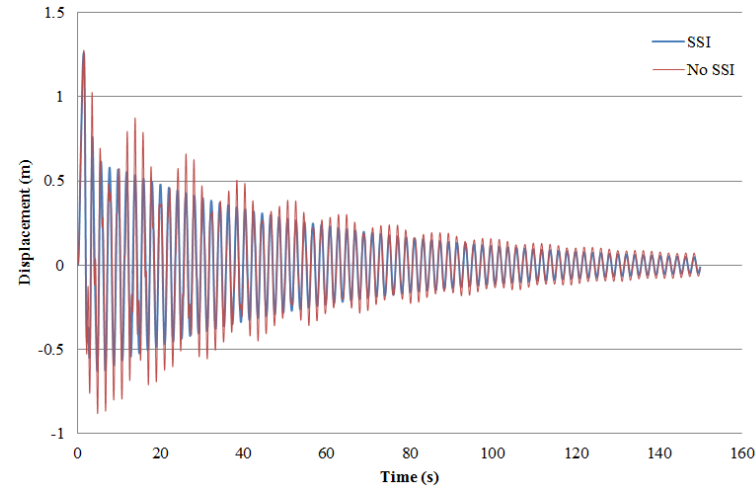

Figure 4.32: Displacement layer 4-30\%

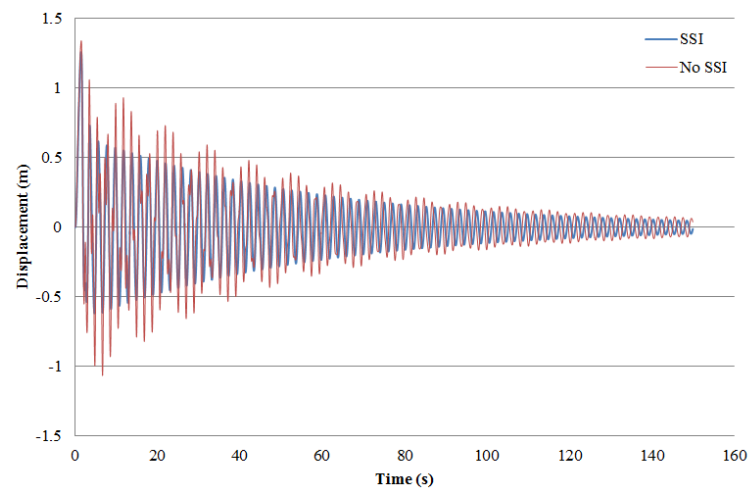

Figure 4.34: Displacement layer 5-30\%

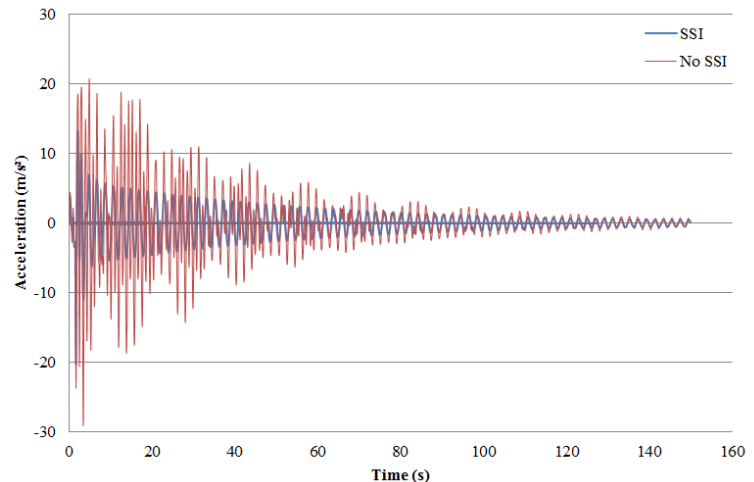

Figure 4.31: Acceleration Layer 3-30\%

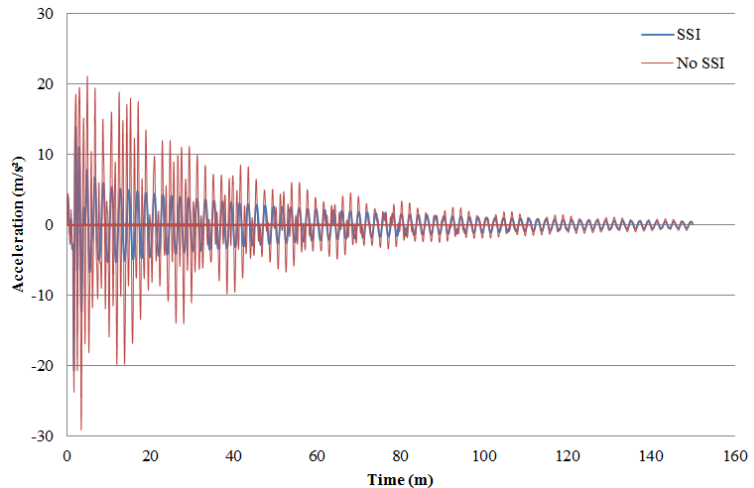

Figure 4.33: Acceleration Layer 4-30\%

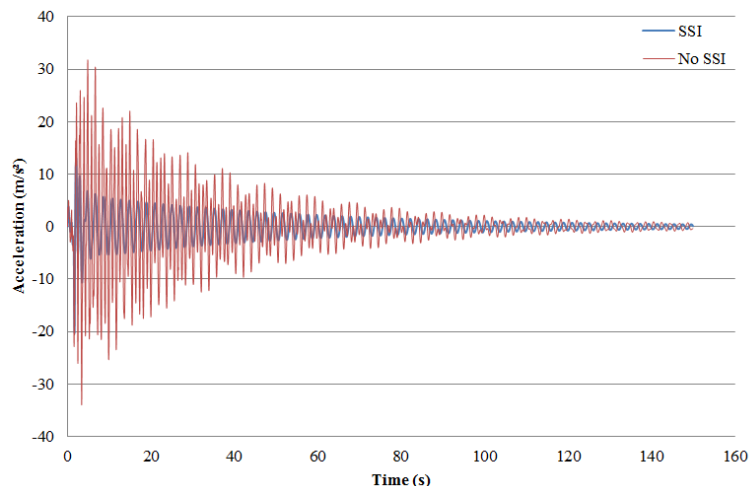

Figure 4.35: Acceleration Layer 5-30\%

Figure 4.36 represents the results from "SAP2000". The obtained results confirm the necessity of considering the SSI effects for an accurate estimation of both the fundamental frequency and equivalent damping of the soil-structure system. 


\begin{tabular}{|c|c|c|c|c|c|c|c|c|c|c|c|c|c|c|c|c|c|c|c|c|c|c|c|}
\hline \multicolumn{4}{|l|}{ Ref. } & \multicolumn{4}{|l|}{ Layer 1} & \multicolumn{4}{|l|}{ Layer 2} & \multicolumn{4}{|l|}{ Layer 3} & \multicolumn{4}{|l|}{ Layer 4} & \multicolumn{4}{|l|}{ Layer 5} \\
\hline MODE & PERIOD & \begin{tabular}{|l|} 
DAMP-RATIO \\
\end{tabular} & SSI\% & PERIOD & DAMP-RATIO & sSI\% $\%$ & Variation SSI \% & PERIOD & \begin{tabular}{|l|l|} 
DAMP-RATIO & \\
DAMIOA
\end{tabular} & |SSI\% & Variation SSI\% & PERIOD & DAMP-RATIO & SSI \% & Variation SSI \% & PERIOD & DAMP-RATIO & SSI \% & |Variation SSI \% & PERIOD & DAMP-RATIO & SI \% & Variation SSI \% \\
\hline 1 & 2.041787 & 0.005863 & 0.086 & 2.041589 & 0.005850 & 0.085 & -1.51 & 2.041395 & 0.005842 & \begin{tabular}{|l|} 
\\
\end{tabular} & -2.43 & 2.041679 & 0.005855 & 0.086 & -0.93 & 2.041668 & 0.005849 & \begin{tabular}{|l|} 
\\
\end{tabular} & -1.62 & 2.041667 & 0.005854 & \begin{tabular}{l|l|l|}
0.085 \\
\end{tabular} & -1.04 \\
\hline & 2.041740 & 0.005857 & 0.086 & 2.041544 & 0.005845 & 0.085 & -1.40 & 2.041350 & 0.005837 & 0.084 & -2.33 & 2.041632 & 0.005850 & 0.085 & -0.82 & 2.041622 & 0.005844 & 0.084 & -1.52 & 2.041621 & 0.005849 & 0.085 & -0.93 \\
\hline & 0.948859 & 0.114823 & 10.982 & 0.945122 & 0.095705 & 9.071 & -17.41 & 0.943869 & 0.089880 & 8.488 & -22.71 & 0.947351 & 0.106978 & 10.198 & -7.14 & 0.946545 & 0.100629 & 9.563 & -12.92 & 0.947657 & 108710 & 10.371 & -5.57 \\
\hline & 0.947850 & 0.111114 & 10.611 & 0.944263 & 92148 & 8.715 & -17.87 & 0.943080 & 0.086495 & 8.150 & -23.20 & 0.946406 & 0.103326 & 9.833 & -7.34 & 0.945627 & 0.097060 & 9.206 & -13.24 & 0.946703 & 0.105064 & 10.006 & -5.70 \\
\hline & 0.890297 & 0.179147 & 17.415 & 0.884339 & 0.204842 & $\mid$\begin{tabular}{|l}
$\mid 19.984$ \\
\end{tabular} & 14.75 & 0.882342 & 0.213841 & 20.884 & 19.92 & 0.888234 & 0.187657 & 18.266 & 4.89 & 0.886841 & 0.189297 & 18.4 & 5.83 & 0.888786 & 0.185442 & 18.044 & 3.61 \\
\hline P & 0.889301 & 0.185525 & 18.053 & 0.883164 & 1215 & 20.622 & 14.23 & 0.881143 & 20016 & \begin{tabular}{|l|}
21.502 \\
\end{tabular} & 19.11 & 0.887180 & $93985 \mid$ & 18.899 & 4.69 & 0.885738 & 195509 & 19.051 & 5.53 & 0.887754 & 191736 & 18.674 & 3.44 \\
\hline & 0.697327 & 0.919464 & 91.446 & 0.695866 & 4315 & 91.932 & 0.53 & 0.693994 & 35006 & \begin{tabular}{|l|}
93.001 \\
\end{tabular} & 1.70 & 0.696586 & 23758 & 91.876 & 0.47 & 0.696771 & 925511 & 92.051 & 0.66 & 0.695682 & 0.925578 & $\mid$\begin{tabular}{|c|}
92.058 \\
\end{tabular} & 0.67 \\
\hline & 0.614028 & 0.107910 & 10.291 & 0.601962 & 79 & \begin{tabular}{|l|l|}
10.608 \\
\end{tabular} & 3.08 & 0.603296 & 0.110672 & $\mid$\begin{tabular}{|l|}
$\mid 10.567$ \\
\end{tabular} & 2.68 & 0.611970 & 0.108063 & 10.306 & 0.15 & 0.611224 & 0.106645 & $\mid 10.165$ & -1.23 & 0.613275 & 0.107684 & $\mid$\begin{tabular}{|c|}
$\mid 10.268$ \\
\end{tabular} & -0.22 \\
\hline & 0.456999 & 0.230381 & 22.538 & 0.454762 & 0.219784 & |21.478 & -4.70 & 0.453211 & 0.207343 & $\mid 20.234$ & -10.22 & 0.455907 & 0.223705 & 21.871 & -2.96 & 0.455644 & 0.220648 & 21.565 & -4.32 & 0.455900 & 0.222728 & \begin{tabular}{|l|}
21.773 \\
\end{tabular} & 40 \\
\hline 10 & 0.450426 & 0.167919 & 16.292 & 0.448884 & 0.154707 & \begin{tabular}{|l|l|}
14.971 \\
\end{tabular} & -8.11 & 0.447853 & 0.142495 & $|13.750|$ & $-15.61 \mid$ & 0.449668 & 0.160249 & 15.525 & -4.71 & 0.449486 & 0.157454 & 15.245 & -6.42 & 0.449665 & 0.159502 & $\mid$ & -5.17 \\
\hline
\end{tabular}

\begin{tabular}{|c|c|c|c|c|c|c|c|c|c|c|c|c|c|c|c|c|c|c|c|c|c|c|c|}
\hline \begin{tabular}{|l} 
Ref. \\
\end{tabular} & & & & Layer 1 & & & & Layer 2 & & & & Layer 3 & & & & Layer 4 & & & & Layer 5 & & & \\
\hline MODE & PERIOD & DAMP-RATIO & SSI \% & PERIOD & \begin{tabular}{|l|} 
DAMP-RATIO \\
\end{tabular} & SSI $\%$ & Variation SSI \% & PERIOD & \begin{tabular}{l|l} 
DAMP-RATIO \\
\end{tabular} & SSI \% & Variation SSI \% & PERIOD & \begin{tabular}{|l|l} 
DAMP-RATIO \\
\end{tabular} & \begin{tabular}{|l|l}
$551 \%$ & $v$ \\
\end{tabular} & Variation SSI \% & PERIOD & \begin{tabular}{l|l} 
DAMP-RATIO \\
\end{tabular} & SSI \% & Variation SSI \% & PERIOD & \begin{tabular}{|l|} 
DAMP-RATIO \\
\end{tabular} & $5 S 1 \%$ & Variation SSI \% \\
\hline 1 & \begin{tabular}{|l|l}
2.041787 \\
\end{tabular} & 0.005863 & $\begin{array}{l} \\
\end{array}$ & \begin{tabular}{|l|}
2.041424 \\
\end{tabular} & 0.005840 & \begin{tabular}{|l|} 
\\
\end{tabular} & $-2.67 \mid$ & \begin{tabular}{|l|l|}
2.041055 \\
\end{tabular} & $\begin{array}{l}0.005824 \\
\end{array}$ & 0.082 & -4.52 & 2.041580 & $\begin{array}{l}0.005848 \\
\end{array}$ & \begin{tabular}{l|l}
0.085 \\
\end{tabular} & -1.74 & \begin{tabular}{|l|l|}
2.041562 \\
\end{tabular} & \begin{tabular}{ll|}
0.005837 \\
\end{tabular} & 0.084 & -3.01 & 2.041566 & \begin{tabular}{|c|c|}
0.005847 \\
\end{tabular} & 0.085 & -1.85 \\
\hline$a_{2}$ & \begin{tabular}{|l|l|}
2.041740 \\
\end{tabular} & 0.005857 & 0.086 & 2.041380 & 0.005835 & 0.084 & $-2.57 \mid$ & 2.041013 & 0.005819 & 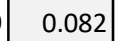 & -4.43 & 2.041535 & 0.005843 & 0.084 & -1.63 & 2.041516 & 0.005832 & 0.083 & -2.92 & 2.041521 & 0.005842 & 0.084 & -1.75 \\
\hline 3 & 0.948859 & 0.114823 & 10.982 & 0.942432 & 080847 & 7.585 & -30.94 & 0.940450 & 0.071147 & 6.615 & -39.77 & 0.946080 & 0.100077 & 9.508 & -13.43 & 0.944713 & 0.089097 & & -23.42 & 946675 & 0.103538 & 9.854 & -10.28 \\
\hline 4 & \begin{tabular}{|l|l|} 
& 0.947850 \\
\end{tabular} & 0.111114 & $\mid 0.611$ & 0.941692 & 077622 & 7.262 & -31.56 & 0.939824 & 68336 & 6.334 & -40.31 & 0.945190 & 96518 & 9.152 & -13.76 & 0.943872 & 0.085738 & 8.074 & -23.91 & 945767 & 0.099968 & 9.497 & -10.50 \\
\hline 5 & \begin{tabular}{|l|l|} 
& 0.890297 \\
\end{tabular} & 0.179147 & 17.415 & 0.878554 & 225682 & 22.068 & 26.72 & 0.874282 & 0.241443 & 23.644 & 35.77 & 0.886290 & 0.194949 & \begin{tabular}{|l|}
18.995 \\
\end{tabular} & 9.07 & 0.883573 & 0.197053 & $\mid 19.205$ & 10.28 & 887440 & 0.190637 & \begin{tabular}{|l|}
18.564 \\
\end{tabular} & 6.60 \\
\hline 16 & \begin{tabular}{|l|}
0.889301 \\
\end{tabular} & 0.185525 & $\mid 18.053$ & 0.877233 & 0.231863 & \begin{tabular}{|l|l|} 
& 22.686 \\
\end{tabular} & 25.67 & 0.872934 & 0.247154 & 24.215 & 34.14 & 0.885184 & 0.201187 & \begin{tabular}{|l|}
19.619 \\
\end{tabular} & 8.68 & 0.882378 & 0.203025 & \begin{tabular}{|c|c|}
19.803 \\
\end{tabular} & 9.69 & 0.886378 & 0.196835 & \begin{tabular}{|l|}
19.184 \\
\end{tabular} & 6.27 \\
\hline 7 & \begin{tabular}{|l|}
0.697327 \\
\end{tabular} & 0.919464 & \begin{tabular}{|l|}
91.446 \\
\end{tabular} & 0.694580 & 0.929394 & 92.439 & 1.09 & 0.691340 & 0.949195 & 94.420 & 3.25 & 0.695866 & 0.927352 & \begin{tabular}{|c|}
92.235 \\
\end{tabular} & 0.86 & 0.696216 & 0.931573 & $|92.657|$ & 1.32 & 694232 & 0.931197 & \begin{tabular}{|l|}
92.620 \\
\end{tabular} & 1.28 \\
\hline 8 & \begin{tabular}{|l|l|} 
& 0.614028 \\
\end{tabular} & 0.107910 & \begin{tabular}{|l|} 
\\
\end{tabular} & 0.591252 & 114099 & 10.910 & 6.01 & 0.593688 & .113145 & 10.815 & 5.09 & 0.609926 & 0.108016 & \begin{tabular}{|l|}
10.302 \\
\end{tabular} & 0.10 & 608819 & 0.105452 & 10.045 & -2.39 & 2524 & 0.107458 & \begin{tabular}{|l|}
10.246 \\
\end{tabular} & -0.44 \\
\hline 9 & & 230381 & 22.538 & 0.452966 & 0.9350 & 20.435 & -9.33 & 0.450310 & 182976 & $\mid 17.798$ & -21.03 & & 217147 & \begin{tabular}{|l|}
21.215 \\
\end{tabular} & -5.87 & & 211359 & 20.6 & -8.44 & & .2159 & 21.093 & -6.41 \\
\hline 10 & \begin{tabular}{|l|l}
0.450426 \\
\end{tabular} & 167919 & \begin{tabular}{|l|}
16.292 \\
\end{tabular} & 0.447683 & 143476 & $\mid 13.848$ & -15.00 & 0.445979 & 0.121203 & 11.620 & -28.67 & 0.449014 & 0.153222 & $\mid$\begin{tabular}{|l|}
$\mid 14.822$ \\
\end{tabular} & -9.02 & 0.448689 & 0.148117 & \begin{tabular}{|l|}
14.312 \\
\end{tabular} & -12.15 & 0.449048 & 0.152424 & 14.742 & \\
\hline
\end{tabular}

\begin{tabular}{|c|c|c|c|c|c|c|c|c|c|c|c|c|c|c|c|c|c|c|c|c|c|c|c|}
\hline \multicolumn{4}{|l|}{\begin{tabular}{|l} 
Ref. \\
\end{tabular}} & \multicolumn{4}{|l|}{ Layer 1} & \multicolumn{4}{|l|}{ Layer 2} & \multicolumn{4}{|l|}{ Layer 3} & \multicolumn{4}{|l|}{ Layer 4} & \multirow{2}{*}{\multicolumn{4}{|c|}{ Layer 5}} \\
\hline MODE & PERIOD & DAMP-RATIO & SSI \% & PERIOD & DAMP-RATIO & $s s \mid \%$ & Variation SSI \% & PERIOD & DAMP-RATIO & ssl\% & Variation SSI \% & & DAMP-RATIO & sSI\% & Variation SSI \% & \begin{tabular}{|l|} 
PERIOD \\
\end{tabular} & DAMP-RATIO & SSI\% & Variation SSI \% & & DAMP-RATIO & $S S 1 \%$ & Variation SSI\% \\
\hline 1 & \begin{tabular}{|l|}
2.041787 \\
\end{tabular} & $\begin{array}{ll}0.005863 \\
\end{array}$ & 0.086 & 2.041274 & 0.005831 & 0.083 & -3.71 & 2.040776 & 0.005809 & 0.081 & -6.26 & \begin{tabular}{|l|}
2.041501 \\
\end{tabular} & 0.005842 & 0.084 & -2.43 & 2.041466 & $\begin{array}{ll}0.005826 \\
\end{array}$ & $\begin{array}{ll}0.083 \\
\end{array}$ & -4.29 & 2.041467 & 0.005839 & 0.084 & -2.78 \\
\hline & \begin{tabular}{|l|}
2.041740 \\
\end{tabular} & 0.005857 & 0.086 & 2.041230 & 0.005826 & 0.083 & -3.62 & 2.040735 & 0.005805 & 0.081 & -6.07 & 2.041456 & 0.005837 & 0.084 & -2.33 & 2.041421 & 0.005821 & 0.082 & -4.20 & 2.041422 & 0.005835 & 0.084 & -2.57 \\
\hline & \begin{tabular}{|l|l|}
0.948859 \\
\end{tabular} & 0.114823 & $\mid$\begin{tabular}{|c|}
10.982 \\
\end{tabular} & 0.940384 & 69210 & 6.421 & -41.53 & 0.938165 & 0.058411 & 5.341 & -51.37 & 0.945047 & 0.094281 & 8.928 & -18.70 & 0.943194 & 0.079425 & 7.443 & -32.23 & 0.945754 & 0.098576 & 9.358 & -14.79 \\
\hline & \begin{tabular}{|l|l|}
0.947850 \\
\end{tabular} & 0.111114 & $\mid$\begin{tabular}{|l|l|}
10.611 \\
\end{tabular} & 0.939740 & 66362 & 6.136 & -42.17 & 0.937651 & 056117 & 5.112 & -51.83 & 0.944202 & . & & -19.12 & 0.942421 & 0.076306 & 7.1 & $-32.80 \mid$ & 944890 & 0.095098 & & | \\
\hline & 0.890297 & 0.179147 & \begin{tabular}{|l|l||}
17.415 \\
\end{tabular} & 0.872911 & 242933 & $\mid$\begin{tabular}{|l|l|}
23.793 \\
\end{tabular} & 36.63 & 0.866877 & 262087 & \begin{tabular}{|l|l|} 
& 25.709 \\
\end{tabular} & 47.63 & 0.884526 & 0.201003 & $|19.600|$ & 12.55 & 0.880392 & 0.203090 & $\mid$\begin{tabular}{|l|}
$\mid$ \\
$\mid$
\end{tabular} & 13.75 & 0.886080 & 0.195562 & 19.056 & 9.43 \\
\hline 6 & 0.889301 & 85525 & $|18.053|$ & 0.871469 & 8869 & | $24.387 \mid$ & 35.09 & 0.865430 & 7382 & 26.238 & 45.34 & 83376 & 207141 & $\mid 20.214$ & 11.97 & 0.879117 & .208795 & 20.380 & 12.89 & 0.884989 & 201647 & 19.665 & 8.93 \\
\hline 7 & 0.697327 & 9464 & |91.446| & 0.693501 & 3963 & | $92.896 \mid$ & 1.59 & 0.689057 & 1348 | & 95.635 & 4.58 & 0.695314 & 0371 & \begin{tabular}{|l|}
92.537 \\
\end{tabular} & 1.19 & 0.695866 & .937132 & 93.213 & 1.93 & 0.693136 & 936476 & \begin{tabular}{|l|l|}
93.148 \\
\end{tabular} & 1.86 \\
\hline & \begin{tabular}{|l|}
0.614028 \\
\end{tabular} & 0.107910 & $\mid 10.291$ & 0.581415 & 116915 & $\mid$\begin{tabular}{|c|}
$\mid 11.192$ \\
\end{tabular} & 8.75 & 0.585292 & 0.115425 & \begin{tabular}{|l|l|l|}
11.043 \\
\end{tabular} & 7.30 & 0.608268 & 0.107935 & \begin{tabular}{|l|}
10.294 \\
\end{tabular} & 0.02 & 0.606449 & 0.104272 & 9.927 & -3.54 & 0.611783 & 0.107136 & \begin{tabular}{|l|l|}
10.214 \\
\end{tabular} & -0.75 \\
\hline & 0.456999 & 0.230381 & |22.538 & 0.451423 & 0.198571 & 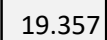 & -14.11 & 0.448223 & 0.161471 & $\begin{array}{l}\mid 15.647 \\
\end{array}$ & -30.57 & 0.454176 & .211544 & 20.654 & -8.36 & 0.453447 & 0.202501 & \begin{tabular}{|l|}
19.750 \\
\end{tabular} & -12.37 & 0.454132 & 0.208928 & \begin{tabular}{|l|}
20.393 \\
\end{tabular} & -9.52 \\
\hline 10 & 0.450426 & 0.167919 & \begin{tabular}{|l|l|}
16.2922 \\
\end{tabular} & 0.446675 & 0.133299 & \begin{tabular}{|l|l|}
12830 \\
\end{tabular} & -21.25 & 0.444667 & 0.105306 & 10,031 & -38.43 & 0.448494 & 0.147499 & 14.250 & -12.53 & 0.448002 & 0.139742 & $\mid 13.474$ & $-17,30$ & 0.448469 & 0.145513 & 14.051 & -13.75 \\
\hline
\end{tabular}

Figure 4.36: Values of SSI obtained from SAP2000 
The figures 4.37 - 4.39 shows the damping percentage by SSI effect in each mode calculated by using SAP2000. The peaks on mode 7 is more than $90 \%$, almost all the damping is produced by SSI, contrary to what happens to the rest of the modes, almost $30 \%$ is by SSI effect.

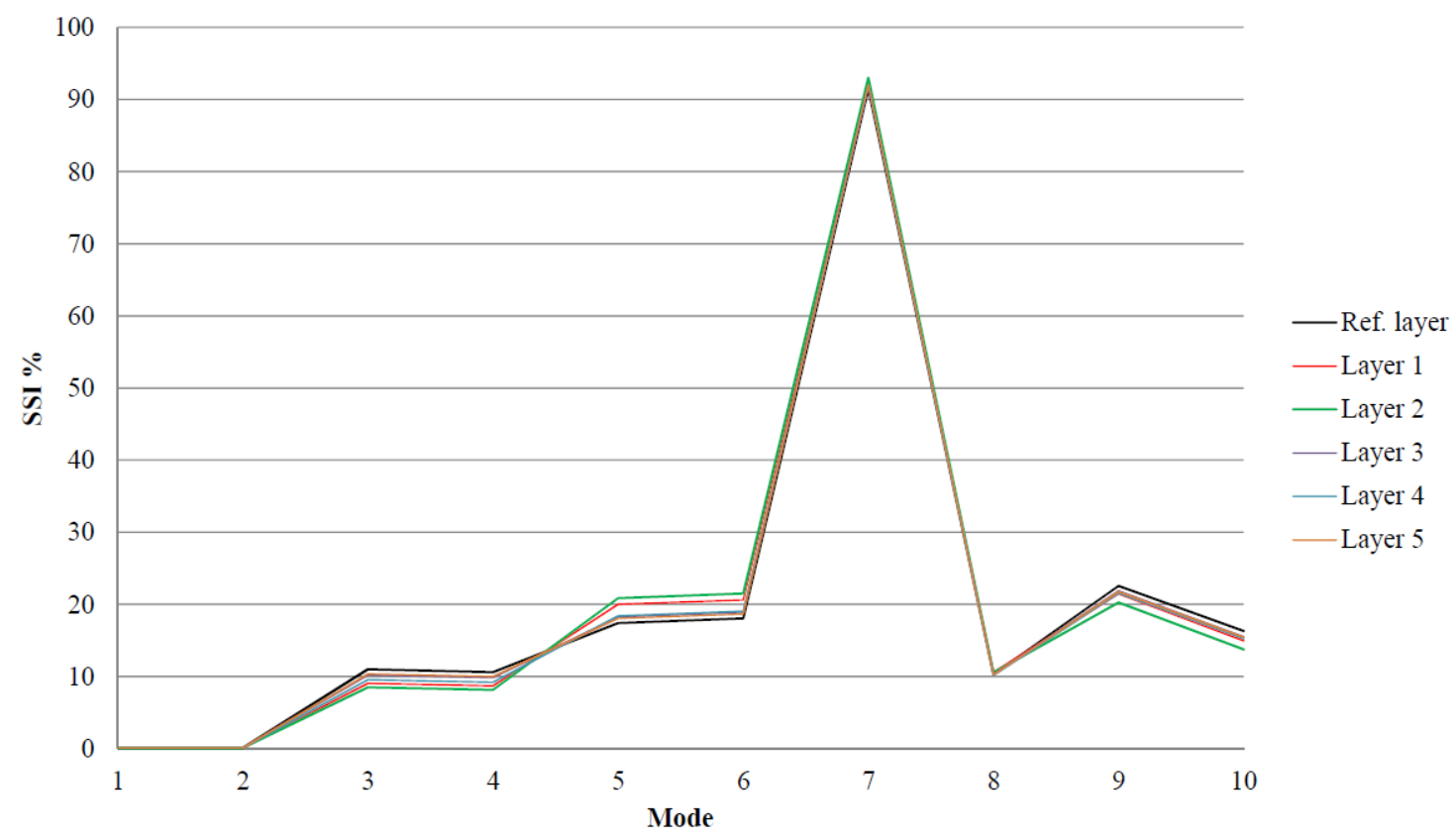

Figure 4.37: SSI-10\%

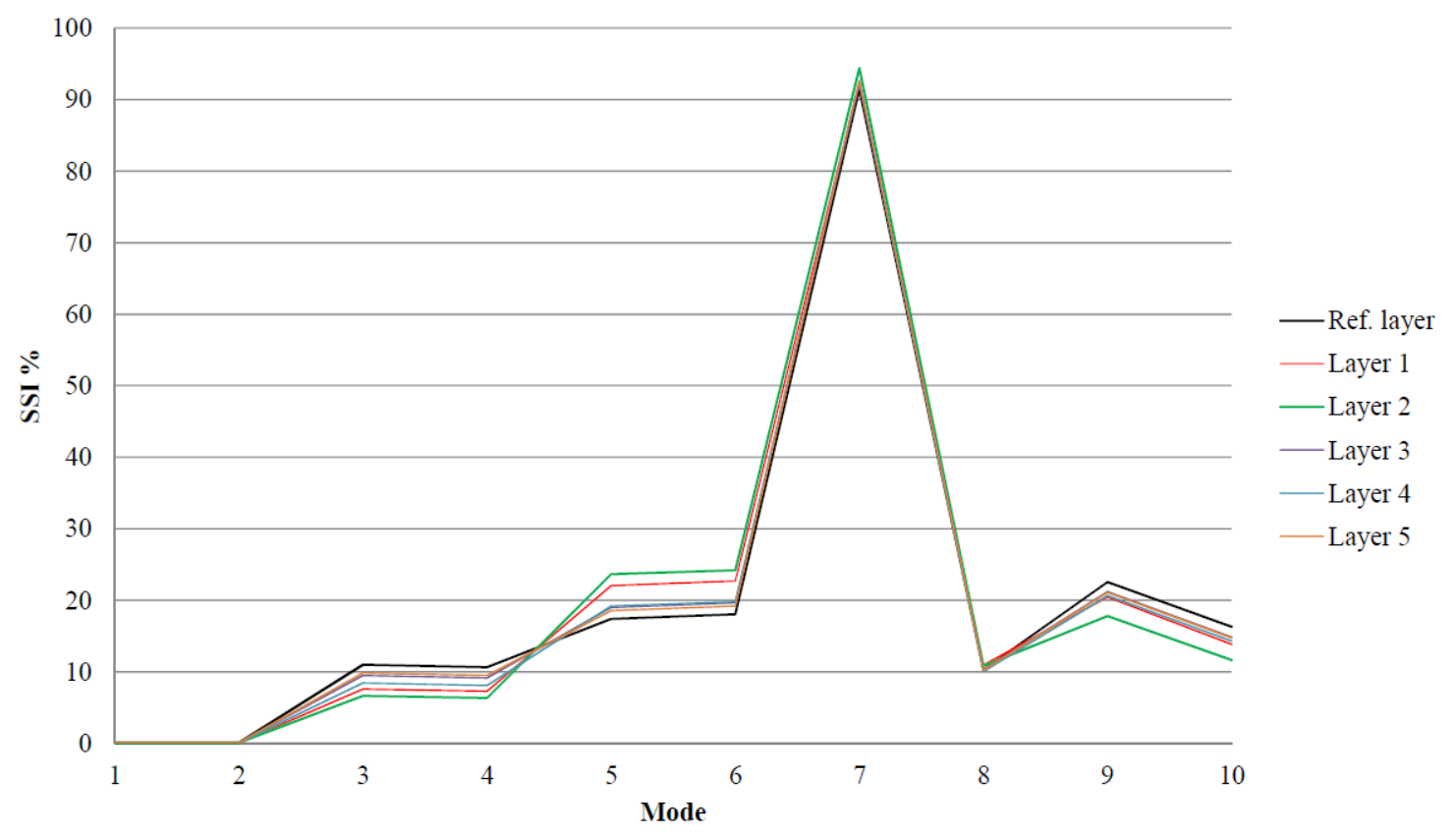

Figure 4.38: SSI-20\% 


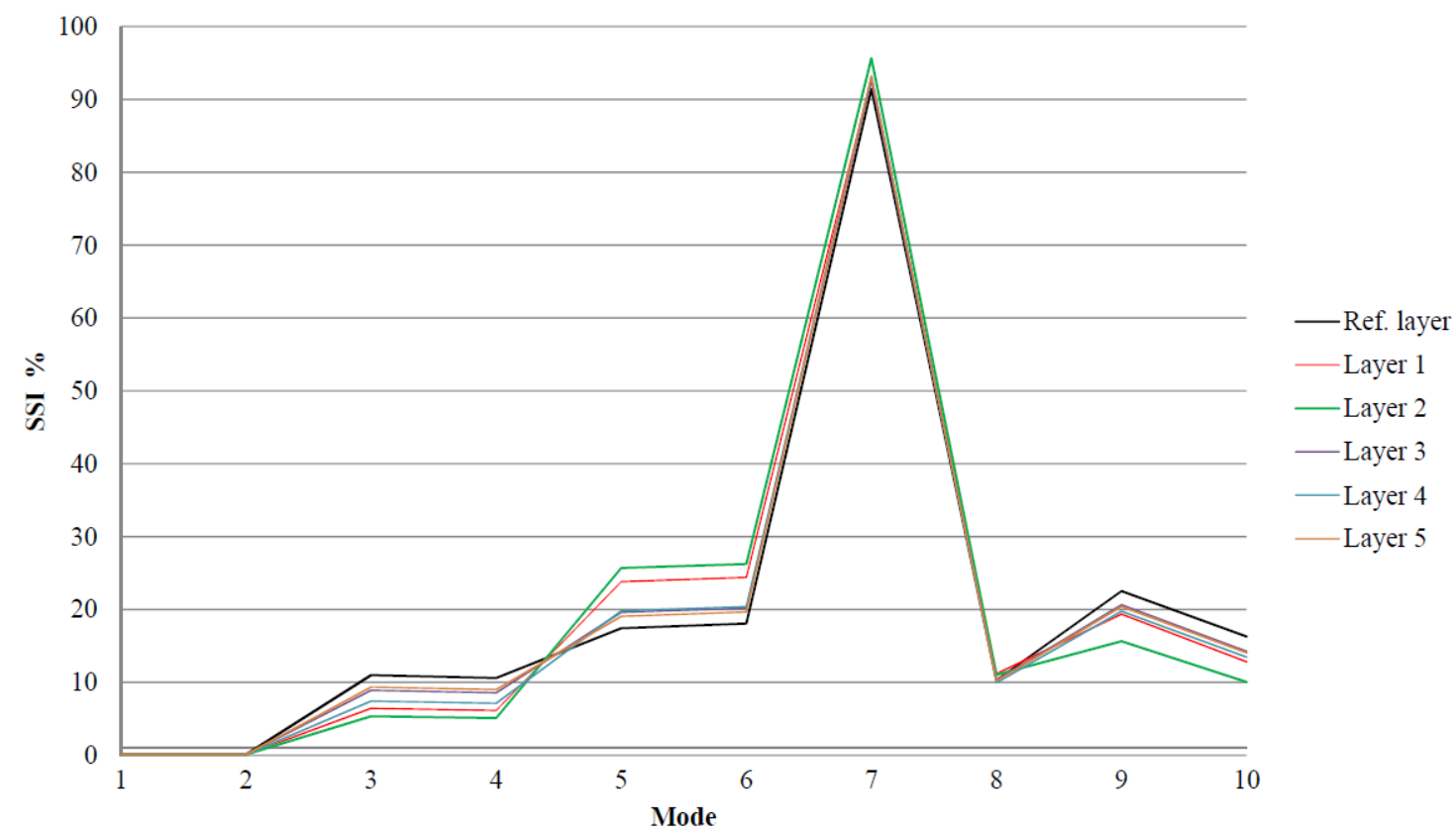

Figure 4.39: SSI-30\%

The figure 4.40 shows that exists linear relation between the variations of Young's Modulus of each layers.

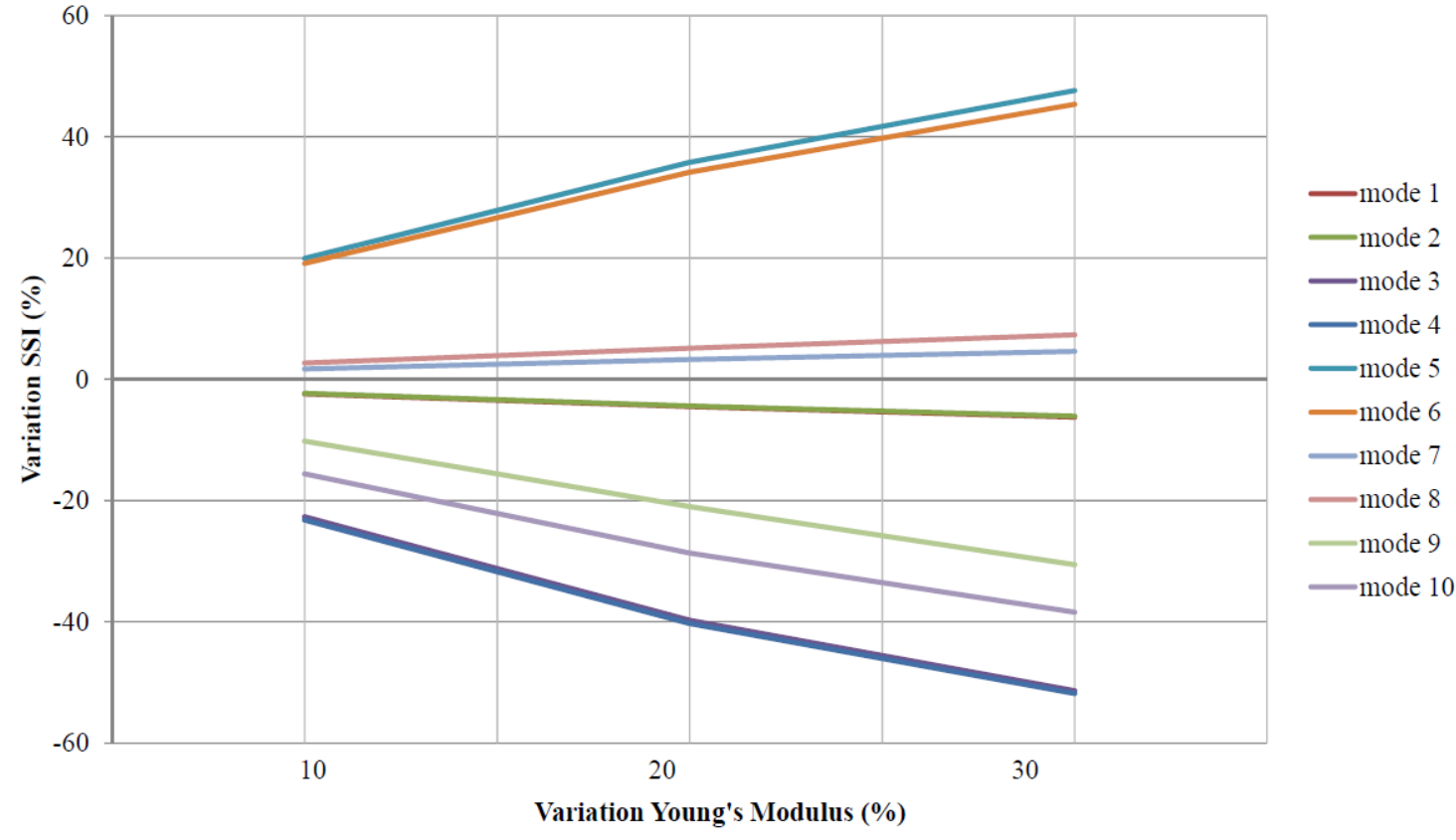

Figure 4.40: Comparison between variations of Young's modulus 



\section{Chapter 5}

\section{Conclusions and future works}

\subsection{Concluding remarks}

In this study, the focus of this work is to evaluate the influence of the multi-layered strata on the magnitude of the soil-structure interaction (SSI) of gravity-based foundations.

By increasing linearly the Young's modulus 10\%, $20 \%$ and 30\%, the damping ratio produced by SSI are $19.92 \%, 35.77 \%$ and $47.63 \%$, respectively. Evidently, from the analysis of the results presented, there is no linear relation between dynamic stiffness and damping ratios of SSI effect. Also it's important to highlight that the layer two is found to play a significant role related to the dynamic stiffness. The magnitude of the stiffness functions tend to increase when the mean Young's modulus of the soil profile increases, with the exception of the vertical mode, for which normalized impedance functions are largely independent of the soil profile. The obtained results confirm the necessity of considering the SSI effects for an accurate estimation of both the fundamental frequency and equivalent damping of the soil-structure system.

In conclusion, the impedance functions have been shown to strongly depend on the soil profile, which highlights the importance of estimating the ground real profile and the need of using it to accurately analyse the dynamic response of the foundation. This can be done by techniques such as MSASW (Multichannel Spectral Analysis of Surface Waves). Typically, this is often ignored or not done well in trials, and usually take samples to analyse static parameters, not dynamic parameters.

In projects, which are strongly influenced by the dynamic aspects (such as the limit state of fatigue in offshore structures) should pay more attention to the coherence of the tests that is asked to characterize the soil by certifiers (DNV-GL, for example). 



\section{Bibliography}

[1] John P Wolf and Andrew J Deeks. Foundation vibration analysis: A strength of materials approach. Butterworth-Heinemann, 2004.

[2] Robert L Higdon. Radiation boundary conditions for elastic wave propagation. SIAM Journal on Numerical Analysis, 27(4):831-869, 1990.

[3] Robert L Higdon. Absorbing boundary conditions for acoustic and elastic waves in stratified media. Journal of Computational Physics, 101(2):386-418, 1992.

[4] Steen Krenk. Unified formulation of radiation conditions for the wave equation. International Journal for Numerical Methods in Engineering, 53(2):275-295, 2002.

[5] Norman A Haskell. The dispersion of surface waves on multilayered media. Bulletin of the seismological Society of America, 43(1):17-34, 1953.

[6] William T Thomson. Transmission of elastic waves through a stratified solid medium. Journal of applied Physics, 21(2):89-93, 1950.

[7] Lars Andersen and Johan Clausen. Impedance of surface footings on layered ground. Computers \&3 structures, 86(1):72-87, 2008.

[8] Lars Andersen. Assessment of lumped-parameter models for rigid footings. Computers Es structures, 88(23):1333-1347, 2010.

[9] Mads Damgaard, Lars Vabbersgaard Andersen, and Lars Bo Ibsen. Assessment of dynamic substructuring of a wind turbine foundation applicable for aeroelastic simulations. Wind Energy, 18(8):1387-1401, 2015.

[10] Lars Andersen and Johan Clausen. Efficient Modelling of Wind Turbine Foundations. InTech, 2011.

[11] JM Emperador and J Dominguez. Dynamic response of axisymmetric embedded foundations. Earthquake Engineering \& Structural Dynamics, 18(8):1105-1117, 1989.

[12] Morten Liingaard, Lars Andersen, and Lars Bo Ibsen. Impedance of flexible suction caissons. Earthquake Engineering \&3 Structural Dynamics, 36(14):2249-2271, 2007.

[13] Lars Andersen and Morten Liingaard. Lumped-parameter models for wind-turbine footings on layered ground. Aalborg University, Department of Civil Engineering DCE Technical Memorandum, 2007.

[14] LV Andersen, Lars Bo Ibsen, and MA Liingaard. Impedance of bucket foundations: Torsional, horizontal and rocking motion. In Proceedings of the Sixth International Conference on Engineering Computational Technology, Athens, Greece. Citeseer, 2008.

[15] Steen Krenk. Mechanics and analysis of beams, columns and cables: a modern introduction to the classic theories. Springer Science \& Business Media, 2001. 
[16] Y Yong, Ruichong Zhang, and J Yu. Motion of foundation on a layered soil medium-i. impedance characteristics. Soil Dynamics and Earthquake Engineering, 16(5):295-306, 1997.

[17] Juan E Luco and Russell A Westmann. Dynamic response of circular footings. Journal of Engineering Mechanics, 1971.

[18] AS Veletsos and VV Damodaran Nair. Torsional vibration of viscoelastic foundations. Journal of the Soil Mechanics and Foundations Division, 100(3):225-246, 1974.

[19] M Novak and K Sachs. Torsional and coupled vibrations of embedded footings. Earthquake Engineering \&3 Structural Dynamics, 2(1):11-33, 1973.

[20] J Avilés and LE Pérez-Rocha. A simplified procedure for torsional impedance functions of embedded foundations in a soil layer. Computers and Geotechnics, 19(2):97-115, 1996.

[21] HL Wong and J Enrique Luco. Tables of impedance functions for square foundations on layered media. International Journal of Soil Dynamics and Earthquake Engineering, 4(2):64-81, 1985.

[22] Akira Mita and J Enrique Luco. Impedance functions and input motions for embedded square foundations. Journal of geotechnical engineering, 115(4):491-503, 1989.

[23] Anestis S Veletsos and Yau T Wei. Lateral and rocking vibration of footings. Journal of the Soil Mechanics and Foundations Division, 97(9):1227-1248, 1971.

[24] S Ahmad and AK Rupani. Horizontal impedance of square foundation in layered soil. Soil Dynamics and Earthquake Engineering, 18(1):59-69, 1999.

[25] Suhol Bu and Chia Hong Lin. Coupled horizontal-rocking impedance functions for embedded square foundations at high frequency factors. Journal of earthquake engineering, 3(04):561-587, 1999.

[26] Mohamed H El Naggar and Milos Novak. Non-linear model for dynamic axial pile response. Journal of geotechnical engineering, 120(2):308-329, 1994.

[27] Mohamed H El Naggar and Milos Novak. Nonlinear axial interaction in pile dynamics. Journal of geotechnical engineering, 120(4):678-696, 1994.

[28] MH El Naggar and Milos Novak. Nonlinear lateral interaction in pile dynamics. Soil Dynamics and Earthquake Engineering, 14(2):141-157, 1995.

[29] MH El Naggar and M Novak. Nonlinear analysis for dynamic lateral pile response. Soil Dynamics and Earthquake Engineering, 15(4):233-244, 1996.

[30] M Hesham El Naggar and Kevin J Bentley. Dynamic analysis for laterally loaded piles and dynamic p-y curves. Canadian Geotechnical Journal, 37(6):1166-1183, 2000.

[31] D Kong, M Luan, X Ling, and Q Qiu. A simplified computational method of lateral dynamic impedance of single pile considering the effect of separation between pile and soils. Recent development of geotechnical and geo-environmental engineering in Asia, page 138, 2006.

[32] Nii Allotey and M Hesham El Naggar. Generalized dynamic winkler model for nonlinear soil-structure interaction analysis. Canadian Geotechnical Journal, 45(4):560-573, 2008. 
[33] Mohammad Mahdi Memarpour, Mehrdad Kimiaei, Mohsenali Shayanfar, and Mostafa Khanzadi. Cyclic lateral response of pile foundations in offshore platforms. Computers and Geotechnics, 42:180-192, 2012.

[34] Lars Vabbersgaard Andersen, MJ Vahdatirad, Mahdi Teimouri Sichani, and John Dalsgaard Sørensen. Natural frequencies of wind turbines on monopile foundations in clayey soils-a probabilistic approach. Computers and Geotechnics, 43:1-11, 2012.

[35] Mads Damgaard, Lars Bo Ibsen, Lars Vabbersgaard Andersen, and Jacob KF Andersen. Cross-wind modal properties of offshore wind turbines identified by full scale testing. Journal of Wind Engineering and Industrial Aerodynamics, 116:94-108, 2013.

[36] Anestis Stavrou Veletsos and B Verbič. Vibration of viscoelastic foundations. Earthquake Engineering \& Structural Dynamics, 2(1):87-102, 1973.

[37] J Enrique Luco. Soil-structure interaction effects on the seismic response of tall chimneys. Soil Dynamics and Earthquake Engineering, 5(3):170-177, 1986.

[38] M Moghaddasi, M Cubrinovski, JG Chase, S Pampanin, and A Carr. Effects of soilfoundation-structure interaction on seismic structural response via robust monte carlo simulation. Engineering Structures, 33(4):1338-1347, 2011.

[39] M Novak and L El Hifnawy. Damping of structures due to soil-structure interaction. Journal of Wind Engineering and Industrial Aerodynamics, 11(1-3):295-306, 1983.

[40] Milos Novak and Laila El Hifnawy. Structural response to wind with soil-structure interaction. Journal of Wind Engineering and Industrial Aerodynamics, 28(1-3):329-338, 1988 .

[41] Eduardo Kausel. Early history of soil-structure interaction. Soil Dynamics and Earthquake Engineering, 30(9):822-832, 2010.

[42] MB Zaaijer. Foundation models for the dynamic response of offshore wind turbines. In Proceedings of MAREC, pages 1-1000, 2002.

[43] Camp T, Morris M, Van Rooij R, Van Der Tempel J, Zaaijer M, Henderson A, and et al. Design methods for offshore wind turbines at exposed sites. final report of the owtes project. Technical report, Garrad Hassan and Partners Ltd, 2003.

[44] J Dominguez. Boundary elements in dynamics. Computational Mechanics Publ. Elsevier, 1993.

[45] Det Norse Veritas. DNV CN 30.4. Foundations, 1992.

[46] Jean-Yves Taillon, Frédéric Légeron, and Simon Prud'homme. Variation of damping and stiffness of lattice towers with load level. Journal of Constructional Steel Research, 71:111-118, 2012.

[47] ASCE. Minimum design loads of building and other structures and commentary, 2010.

[48] MJ Glanville, KCS Kwok, and RO Denoon. Full-scale damping measurements of structures in australia. Journal of wind engineering and industrial aerodynamics, 59(2):349364, 1996.

[49] N/A. AASHTO LRFD Bridge Design Specifications. AASHTO, 2010.

[50] CSA. CAN/CSA-S6-06.Canadian highway bridge design code and S6 S1-10, 2010. 
[51] N/A. AISC Seismic design manual. AISC, 2008.

[52] British Standard. Eurocode 1: Actions on structures-part1-4: General actions-wind actions; bs en 1991-1-4. British Standard Institution, London, 2005.

[53] Price Code. Eurocode 8: Design of structures for earthquake resistance-part 1: general rules, seismic actions and rules for buildings, 2005.

[54] Det Norse Veritas. Guidelines for Design of Wind Turbines, 2009. 